\title{
Analytical determination of the discharge characteristics of broad-crested weirs using boundary layer theory
}

by

\author{
G. W. Hall, B.Sc.(Eng.), Ph.D., A.M.I.Mech.E.
}

Professor Steponas Kolupaila (Department of Civil Engineering, University of Notre Dame, Indiana, U.S.A.) wrote that the problem of flow over a broad-crested weir was assumed to have been definitely solved in 1843 , when J. B. Bélanger proposed his famous minimum-energy postulate. Nevertheless, more than 100 papers on that 'simple' matter had appeared in different languages over the century. In addition to the Author's references, some fifty were annotated in a recently-published bibliography. ${ }^{24}$

63. The Author's efforts to revise this old problem in the light of modern boundary layer theories were of great interest. After separating the turbulent boundary layer from the nappe over a horizontal weir crest of unlimited width, the Author derived his analytical equations (4) and (5), expressed in terms of the Reynolds number. These formulae were checked on two series of experiments made by H. Bazin before 1896 .

64. A theoretical limit of a free outflow, undisturbed by submergence, was explained in $\$ 28$, which needed some comments. A direct substitution of the empirical formula

$$
\left(U_{\mathrm{d}} / U_{1}\right)^{2}=0.5
$$

into the continuity equation

$$
0.6 H U_{1}=(\sigma-0.1) H U_{\mathrm{d}}
$$

resulted in a $\sigma$-value of 0.95 instead of 0.85 .

65. The energy equation, supplemented according to Fig. 2,

$$
0.6 H+U_{1}^{2} / 2 g=(\sigma-0.1) H+U_{\mathrm{d}}^{2} / 2 g=0.9 H
$$

led to an indefinite relationship

$$
\sigma=1-0.3\left(U_{\mathrm{d}} / U_{1}\right)^{2}
$$

which, solved with the continuity equation, resulted in $\sigma=0 \cdot 70$, and corresponded to $U_{\mathrm{d}}=U_{1}$.

66. The empirical relationship $\left(U_{\mathrm{d}} / U_{1}\right)^{2}=0 \cdot 5$, introduced into the energy equation, yielded the value $\sigma=0 \cdot 85$, as obtained by the Author. This result, however, did not satisfy the continuity condition.

67. The Author had simplified his derivation for frictionless flow and uniform velocity distribution. It seemed to be more reasonable to take a real flow with a parabolic or logarithmic law of velocity variation, and, consequently, correct the velocity heads in the Bernoulli formula. Such improvement should be particularly significant in the solution of $\S 28$. Correcting appropriately, e.g. $1 \cdot 15\left(U_{1}^{2} / 2 g\right)$ and $1 \cdot 30\left(U_{\mathrm{d}}^{\mathrm{a}} / 2 \mathrm{~g}\right)$, the resulting $\sigma=0.83$ would agree much more closely with the value suggested by Dr Engel.

\footnotetext{
* Proc. Instn civ. Engrs, vol. 22, June 1962, pp. 177-190.
} 
68. Equations (4) and (5) were in implicit form, since the Reynolds numbers depended on an unknown velocity, and were therefore inconvenient for practical application. An appropriate nomogram had to be designed, in order to avoid tiresome solution by trial and error procedure.

Dr N. Rajaratnam (Senior Scientific Officer, Civil Engineering and Hydraulics Department, Indian Institute of Science, Bangalore) wrote that Dr Hall should be commended for his attempt on this problem of boundary layer flow with gravity interaction and preceded by separation.

70. From a systematic study recently conducted in the Hydraulic Research Laboratory of the Indian Institute of Science, Bangalore, on 'Discharge characteristics of weirs of finite crest-width,' ${ }^{25}$ it had been found that the flow could be divided into four regions as given below.

$$
\text { Region 1. Long-crested weir } 0<\frac{H}{L} \leqslant 0 \cdot 1
$$

where $H$ was the head over the crest and $L$ the length of the crest in the direction of flow.

Region 2. Broad-crested weir $0.1 \leqslant \frac{H}{L} \leqslant 0.4$

Region 3. Narrow-crested weir $0.4 \leqslant \frac{H}{L} \leqslant 1.5$ to 1.9 ,

depending on the value of $H / P$ where $P$ was the height of the crest above the bed of the approach channel.

\section{Region 4. Sharp-crested weir 1.5 to $1.9 \leqslant \frac{H}{L}$.}

71. In the broad-crested weir range, the discharge coefficient in the equation $q=\mathrm{CH}^{3 / 2}$ was given by the equation

$$
C=0 \cdot 15 \frac{H}{L}+2 \cdot 82 \text {. }
$$

It was easy to see that Hall's analysis applied strictly to this case only.

72. From the investigations of Woodburn, ${ }^{26}$ Rouse $^{27}$ and the analysis of Tracy, ${ }^{6}$ it was known that for a broad-crested weir with a sharp crest, the depth of flow on the crest was always less than the critical depth (for parallel flow) and as such the use of the ideal equation $(\$ 4)$

$$
q_{1}=(2 / 3)^{1 \cdot 5} g^{0.5} H^{1 \cdot 5}
$$

was not completely correct unless another coefficient was introduced into the above equation.

73. Thirdly, for the case of the broad-crested weir with a rounded entrance, it was known that the boundary layer thickness increased up to a maximum, forming a virtual throat for the flow and then decreased. If such a thing applied to this case also, then the formulation of the Author's equation (2) might not be correct. This could be verified by the study of the growth of the re-attached turbulent boundary layer in a way similar to that of Delleur.

74. Regarding the modularity limit, the Author's hypothesis that it was because of the boundary layer separation was not very convincing. It had recently been shown ${ }^{28}$ that for the broad-crested weir the modularity limit $(\sigma)$ was constant at 0.85 for $H / L$ from 0.1 to 0.2 and then fell off to 0.74 at $H / L=0.4$, i.e. at the end of the broad-crested weir range. Thus it was seen that $\sigma$ was not a constant for the broad-crested weir range. Further, the assumption of $\delta_{\max }=0.100 \mathrm{H}$ in the derivation of $\sigma$ was again very approximate. From his considerable experience in conducting modularity limit studies on different weir shapes ${ }^{29-31}$ (both in the Indian Institute of Science and the 
Irrigation Research Station, Poondi, Madras), Dr Rajaratnam considered that the modularity phenomenon was connected with wave celerity and the flow control on the weir by the critical depth section.

75. The application of 'free streamline theory' in the computation of $K$ in $\S 33$ did not seem to be correct because of the severe curvature imposed on the flow on the upper surface. In $\S 57$, it was not clear why the Author was using the $C_{\mathrm{c}}$ value for the three dimensional flow (axisymmetric case) when he was dealing only with the twodimensional case. If he had taken $C_{\mathrm{c}}$ for the two dimensional case, he would have obtained a factor of 0.195 instead of 0.109 .

76. Regarding the Author's interesting model of the separation bubble, it should be stated that he had taken the angle of $15^{\circ}$ from Von Doenhoff's hypothesis suggested for the separation bubble formed on a curved surface and which itself was now generally regarded as not accurate enough to furnish quantitative information. ${ }^{32}$ Furthermore, there was doubt whether the flow separation forced at the intersection of two plane surfaces was exactly equivalent to that which produced a short bubble on the curved (airfoil) surface. A short account of the short and long bubble could perhaps have been added by the Author.

77. On a surface of finite radius, for a short bubble to form, it had been shown ${ }^{32}$ that the Reynolds number based on displacement thickness at the upstream separation point should be in a critical range (criterion of Tani, Owen and Klanfer) and that the pressure recovered in the re-attachment process should be less than a certain critical value (Crabtree criterion). These criteria might not apply to the separation at a $90^{\circ}$ corner. Some information regarding the separation bubble for a $90^{\circ}$ inlet and blunt shaft (axisymmetric case) had been obtained recently by Rouse, ${ }^{33}$ but when there was an interaction by the gravitational field, there might be some additional variation.

78. It would be very useful if the Author could furnish the unpublished computations of Maskell which gave him some information regarding the thickness of the re-attached turbulent boundary layer. In view of the complications involved in this problem, it was suggested that some basic data be collected first before any general theory was advanced. In this connexion, it might be mentioned that Dr Rajaratnam was presently conducting an investigation to obtain information regarding the separation bubble for the broad-crested weir.

Professor Masashi Hom-ma (Department of Civil Engineering, University of Tokyo) wrote that though the free flow over a broad-crested weir was affected by the entry condition and the crest length $L$, it was always transformed from a subcritical to a supercritical state in the course of flow over the weir. There was therefore a transition section on the crest of weir.

80. The equation of flow rate

$$
q=(2 / 3)^{1 \cdot 5} g^{0.5}\left(H-\delta^{*}{ }_{\max }\right)^{1.5}
$$

could be introduced from Bernoulli's theorem by using the assumptions (Fig. 6), that

(a) $\delta^{*}$ took its maximum at the transition where the depth over the boundary layer was $2 / 3\left(H-\hat{\delta}^{*}{ }_{\text {max }}\right)$,

(b) the vertical distribution of pressure in this section was hydrostatic.

81. The Author's flow model shown in Fig. 1(b) had $\delta^{*}{ }_{\max }$ at the end section of the crest. But this section seemed to be inadequate to be taken into the basis of theoretical consideration from the following reasons:

(a) the assumption of hydrostatic distribution of pressure did not hold good in this section,

(b) the transition section was generally considered to exist near the entry.

82. Concerning the boundary layer downstream of the separation bubble, its reasonable depth could be deduced from the fundamental equation of open channel 
flow, as was shown in the research of Delleur. ${ }^{2}$ But the theoretical treatment of boundary layer, including the neighbourhood of sharp entry, was very difficult, though the sharp-edge shape was clearly practical. The precise measurement of velocity distribution in the flow over a broad-crested weir of various proportions might be very helpful for the future study of the problem.

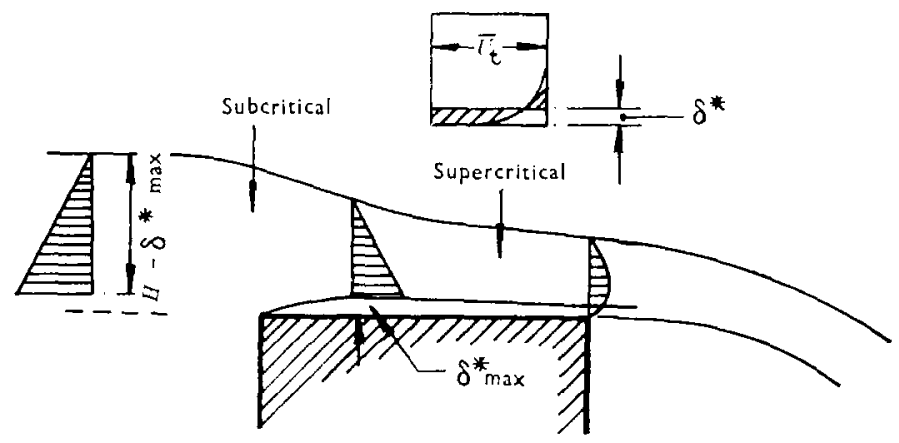

FIG. 6

Dr Roderick Agnew (Downer \& Co. Ltd, Auckland, New Zealand) congratulated the Author on a stimulating Paper. His simplified flow model was capable of further development, for dimensional analysis showed that the discharge coefficient was a function of the roughness ratio $H / \epsilon$ as well as the Reynolds and Froude numbers. When the weir crest was hydraulically rough, as in many civil engineering applications, the Reynolds number effect might be negligible. Then the boundary layer would thicken with distance $x$ from the virtual origin in accordance with an equation such as

$$
\frac{\delta}{x}=0.024\left(\frac{x}{\epsilon}\right)^{-0.13}
$$

due to Bauer, ${ }^{34}$ as quoted by Ven Te Chow. ${ }^{35}$ Assuming a velocity distribution according to the $\frac{1}{7}$ th power law, the displacement thickness $\delta^{*}=\frac{1}{8} \delta$ was given by

$$
\frac{\delta^{*}}{x}=0.003\left(\frac{x}{\epsilon}\right)^{-0.13} \text { whence } \frac{\delta_{\max }^{*}}{l}=0.003\left(\frac{l}{\epsilon}\right)^{-0.13}
$$

Substituting in equation (1) and eliminating $l$ by the Author's procedure of $\S 17$, one arrived at the following expression for discharge coefficient:

$$
1-C=0.0045\left\{\frac{L}{H}-1+k\left(\frac{H}{\epsilon}\right)^{0.15}\right\}^{0.87}\left(\frac{H}{\epsilon}\right)^{-0.13}
$$

84. The factor $k$ was equal to $60 \cdot 3$ if $\delta^{*}=0 \cdot 109 H$ at $L / H=1$, the pivot co-ordinates used by the Author, which depended on the height of the separation bubble. This was influenced by the roughness and slope of the upstream face. It might be possible to calculate $k$ for a range of these variables, and also as a function of the velocity of approach, by a treatment similar to that for the Author's $k$ factor.

85. Assuming that $k=60 \cdot 3$ in equation (8), it was interesting to compare values of $C$ by the different theories with Bazin's experimental values in Series 115, part of which was given in Table 4. 
TABLE 4

\begin{tabular}{l|c|c|c|c}
\hline $\begin{array}{c}H \\
(\mathrm{ft})\end{array}$ & $\begin{array}{c}\epsilon_{11 \mathrm{~m}} \\
(\mathrm{ft})\end{array}$ & $C_{\mathrm{ex}}$ & $\begin{array}{c}C_{\text {th }} \\
(\text { Smooth) }\end{array}$ & $\begin{array}{c}C_{\mathrm{th}} \\
\text { (Rough) } \\
- \text { eqn (8) }\end{array}$ \\
\hline 0.196 & 0.0006 & 0.729 & 0.740 & 0.803 \\
$\mathbf{0 . 4 1 5 8}$ & 0.0004 & $\mathbf{0 . 8 1 0}$ & 0.805 & 0.825 \\
$\mathbf{0 . 6 4 0 7}$ & 0.0003 & $\mathbf{0 . 8 1 6}$ & $\mathbf{0 . 8 2 2}$ & 0.831 \\
$\mathbf{0 . 8 7 8 2}$ & 0.0003 & $\mathbf{0 . 8 3 2}$ & $\mathbf{0 . 8 2 9}$ & 0.834 \\
$\mathbf{1 . 1 0 8 9}$ & 0.0003 & $\mathbf{0 . 8 3 6}$ & $\mathbf{0 . 8 3 2}$ & 0.836 \\
$\mathbf{1 . 3 4 8}$ & $\mathbf{0 . 0 0 0 2}$ & $\mathbf{0 . 8 4 9}$ & $\mathbf{0 . 8 3 5}$ & 0.837 \\
1.492 & 0.0002 & $\mathbf{0 . 8 5 2}$ & 0.836 & 0.838 \\
\hline
\end{tabular}

86. In preparing Table 4 , an equivalent sand roughness $\epsilon=0.0020 \mathrm{ft}$, typical of planed wood or neat cement, was used. Over the range of heads tested, this exceeded the limiting roughness $\epsilon_{1 \mathrm{~m}}=100 H / R_{\mathrm{H}}$ quoted by the Author $(\S 41)$, although not by a sufficient margin at the lower discharges to ensure completely 'rough' conditions. It would be noted that the greatest divergence between $C_{\text {th (Rough) }}$ and $C_{B x}$ occurred at the lowest head. There was less than $2 \%$ difference in the case of heads above 5 in.

87. Even better agreement might be secured if reliable information was available on the actual roughness of the weir surfaces used in Bazin's experiments. However, it was unlikely that one formula would be found to cover every case. For the foreseeable future $C$ had to remain an empirical coefficient, although a clear understanding of why it varied was necessary for intelligent and economical design of metering devices.

88. Finally, the Author might seek more recent experimental data from Professor C. E. Kindsvater of Georgia Institute of Technology, Atlanta, where research was being carried out on internal characteristics of the flow pattern, including the boundary layer, over two-dimensional models of flooded highway embankments having different surface roughnesses.

Mr R. A. Wallis (Aeronautical Research Laboratories, Department of Supply, Australia) wrote that of particular merit, in this excellent and ambitious Paper, was the Author's stated objective, as in $\S 3$; the complexity of the problem, however, prompted Mr Wallis to suggest that some 'bubble' stabilizing device must be introduced if precision was to be obtained in computation and measurement. He would now elaborate on this theme.

90. The experimental results of Bazin had been plotted in Fig. 7. Both curves possessed certain similarities, namely:

(a) a steep initial rise in $C_{\mathrm{ex}}$ with Reynolds number;

(b) a levelling-off to a constant value of approximately 0.837 ; and

(c) a sudden increase at the highest experimental Reynolds numbers.

This latter feature had been attributed by the Author to a decreasing bubble height. The other points, however, were also worthy of some comment.

91. At very low Reynolds numbers the separated laminar layer would re-attach to the crest in a laminar state, provided the crest length, $L$, was not small. This argument was based on such factors as the lack of an adverse pressure gradient over the aft portion of the crest and the inability of turbulence to exist in the presence of the relatively large viscous forces. With increase of Reynolds number, the separated shear layer would become unstable in the transverse direction, that is, it would tend to wrinkle on a scale greater than the shear layer thickness. Turbulence would eventually be produced and the flow would re-attach as a thick turbulent boundary layer. 
92. The next stage with increasing Reynolds number would be the one outlined in the Paper. Mr Wallis, however, would like to draw attention to experimental data which supported the view that transition was not complete until after re-attachment and which further suggested that the point $T$ only marked the onset of the stable turbulent mixing so essential to transition. ${ }^{36}$

93. Reference 36 also provided evidence that a major change in bubble structure occurred at high Reynolds numbers. It would appear that a small-scale transverse disturbance, conducive to transition, occurred just after separation, thus causing a rapid reduction in bubble dimensions. Once this Reynolds number range had been traversed, the value of $C_{\mathrm{Bx}}$ would again be relatively constant with further increases in Reynolds number. It was unfortunate that Bazin's results did not extend up to these very high Reynolds numbers.

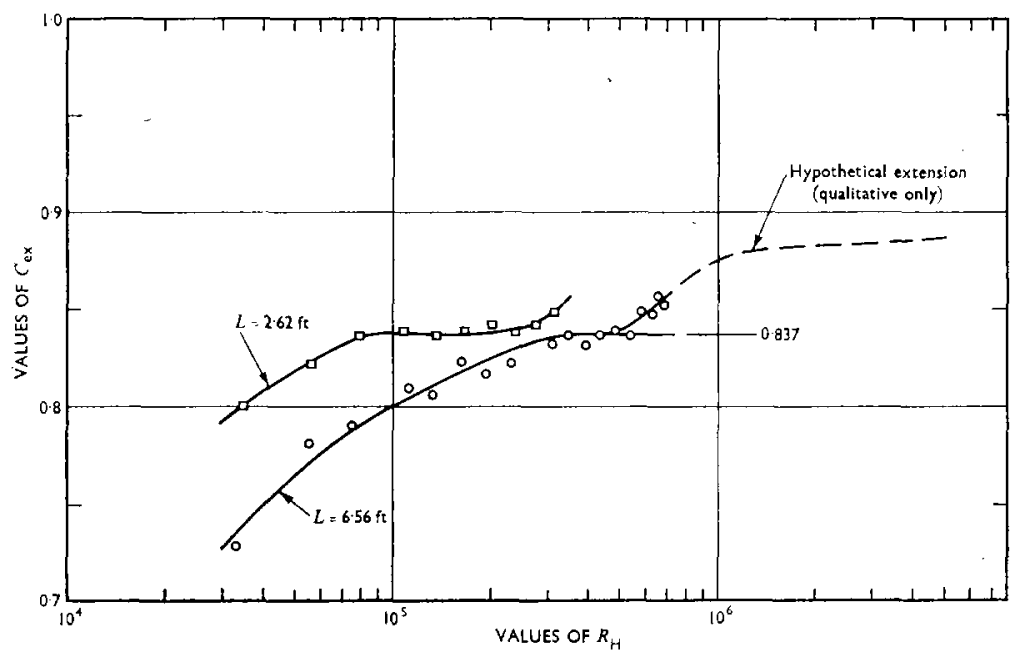

FIG. 7

94. From the data of Fig. 7, the length of crest showed as a variable, not only because of boundary layer thickness effects, but because of the change in the value of $R_{\mathrm{H}}$ at which the sharp rise in $C_{\mathrm{ex}}$ occurred. When other factors such as roughness, channel depth, crest-entry shape, side walls, etc., were also taken into consideration, the problem of achieving the desired degree of accuracy in prediction became a formidable one.

95. Since, however, the laminar separation bubble provided the key to the whole situation, the Author was to be commended for his Paper. Mr Wallis personally believed that the problem would only become tractable when measures were taken to control transition within the separated layer. Work on aerofoils with roughness, vortex generators and air jets had demonstrated the ability of these devices, when carefully designed and located, to eliminate major Reynolds number effects over an appreciable range of flow conditions. ${ }^{36}$ In the present instance, vane type vortex generators of relatively small scale could, with advantage, be attached to the crest entry. This was only one of a number of possibilities which should be investigated in relation to the question of producing a more predictable transition phenomenon.

96. Provided a satisfactory solution could be found to the above problem, work could then commence on minimizing the effect of upstream and side-wall influences 
on the flow over the crest. Data missing from the present Paper, but which would be vital to such a study, were boundary layer growth and thickness upstream of the crest entry, the position of stagnation points and the streamwise pressure distributions along the weir crest.

97. Mr Wallis pointed out that the possibility of transition occurring, as indicated in Fig. 3, was very remote. Instead, transition would be a gradual process, thus making a marked reduction in displacement thickness unlikely. However, there would be a change in $d \delta^{*} / d x$ and this could initiate a stationary wave on the weir crest.

98. Finally, Mr Wallis could not support too strongly the type of approach followed by the Author which he was sure would eventually lead to a practical solution of this most difficult problem.

Mr P. Ackers and Mr A. J. M. Harrison (Hydraulics Research Station, Wallingford) wrote that they had been interested to read the Paper as they had recently made a study of the design of trapezoidal-throated measuring flumes which included a theoretical calibration method using the critical depth and boundary layer theories. ${ }^{37}$

100. A number of points made in the Paper warranted further consideration. For instance, the Author assumed that the 'bubble' height ( $\$ 110,56$ and 57) for a small velocity of approach was $0 \cdot 109 \mathrm{H}$, basing this on an analogy with the lower nappe profile of a thin plate weir, and the contraction coefficient of a slot or square-edged circular orifice. However, if there was agreement, it appeared to be fortuitous, since these analogues did not satisfy the conditions at a broad-crested weir where the flow was not axisymmetric as in the case of a slot and the bubble pressure was not atmospheric as it was in both the suggested analogues. ${ }^{38}$ It was unlikely that the bubble geometries would be alike when the pressures differed, for the nappe curvature was a function of the pressures acting upon it.

101. The Author's Table 1 was computed on the assumption that $U_{\mathrm{t}}=(2 \mathrm{gH} / 3)^{0.5}$. In fact, the velocity would be somewhat higher than had been assumed, because experimentally-determined water surface profiles showed a depth on the crest of about $0.5 \mathrm{H}^{39}$ rather than $0.7 \mathrm{H}$ as indicated in Fig. 2. The lesser depth might nevertheless represent critical conditions if account was taken of head losses in the vicinity of the bubble.

102. The assumption was made by the Author in $\S 9$ (and also by Ippen ${ }^{1}$ ) that the effective head on the crest was $H-\delta^{*}$. The proof was not given, so the following derivation, originally suggested by Professor C. M. White, was presented.

103. Outside the boundary layer the velocity was accurately represented by the Bernoulli equation:

$$
U=[2 g(H-d)]^{1 / 2}
$$

where $d$ was the depth of flow on the crest.

104. From the definition of the boundary layer displacement thickness, the continuity equation could be expressed as

$$
q_{r}=U\left(d-\delta^{*}\right)
$$
to $d$,

105. Substituting equation (9) in equation (10) and differentiating with respect

$$
\frac{d q_{\mathrm{r}}}{d d}=-g\left(d-\delta^{*}\right)[2 g(H-d)]^{-1 / 2}+[2 g(H-d)]^{1 / 2} .
$$

Assuming critical flow conditions, i.e. that maximum discharge occurred for a given head,

and

$$
\frac{d q_{\mathrm{r}}}{d d}=0
$$

$$
d=\frac{2}{3} H+\frac{1}{3} \delta^{*}
$$


106. Combining equations (9), (10), and (11), the Author's equation was obtained:

$$
q_{\mathrm{r}}=\frac{2}{3} \sqrt{\frac{2}{3} g}\left(H-\delta^{*}\right)^{3 / 2} .
$$

107. In $\$ 41$ a limiting value of roughness, $\epsilon_{11 \mathrm{~m}} / H=100 / R_{\mathrm{H}}$, was quoted. In the two examples of Table 1 the calculated value of $\epsilon_{1 \mathrm{~m}}$ lay in the range 0.0002 to $0.0005 \mathrm{ft}$, and a surface of this roughness ${ }^{39}$ would be painted metal, for example. Mr Ackers and $\mathrm{Mr}$ Harrison did not know the composition of the surfaces of Bazin's weirs but suspected that the roughness might have been somewhat greater than the limiting values quoted. Certainly, in a practical design when the weir surface might be concrete of roughness $0.002 \mathrm{ft}, \delta^{*}$ would also be a function of the relative roughness, a condition not covered in the Paper.

108. The Author was to be congratulated on producing a theory fitting so accurately to Bazin's data, despite the criticisms made in the above paragraphs. This good fit was achieved perhaps because the crest friction term had only a small influence on the overall coefficient. For example, an error of $5 \%$ in the allowance for the boundary layer development at the lowest head would alter $C_{\text {th }}$ by less than $1 \%$. Any error in the assumed height of the separation bubble would have been expected to have a greater influence, and it would be interesting to learn whether any actual measurements had been made of the geometry of the separation zone.

109. To ensure essentially parallel flow at the critical section, the Author suggested a lower limit for $L / H$ of 3 . However, the plots of Bazin's data ${ }^{5}$ for crest lengths of $0.66,1.32$ and $2.62 \mathrm{ft}$ showed a change of slope at an $L / H$ value of about 2 , indicating a less severe limit at which curvature of flow on the crest affected the coefficient. This figure compared with values of 1.5 to 2 for rounded-entry broad-crested weirs and long-throated flumes. ${ }^{37}$

110. It was considered that caution should be used in applying the theory at very low heads, as there was some evidence ${ }^{40}$. that the coefficient rose again as the head reduced when $P / H$ was greater than about 10 . This was probably due to the development of a boundary layer on the front face of the weir affecting the flow conditions in the region of the bubble. It was interesting that a similar effect was observed with thin-plate weirs. ${ }^{41}$

111. The problem of submergence was complex and had been studied very little. Further research was desirable, but $\mathrm{Mr}$ Ackers and $\mathrm{Mr}$ Harrison could not agree that Fig. 2 correctly indicated the flow conditions at incipient submergence, since the existence on the crest of the depth $\sigma H$, greater than the critical depth occurring further upstream, implied a spontaneous creation of energy. (For large values of $L / H$ standing waves did appear on the crest but these were caused by unstable flow conditions when the Froude number was close to unity and, because of the curvatures involved, did not depend on energy change.)

112. Mr Ackers and Mr Harrison understood the submergence limit as the tailwater limit at which an hydraulic jump (not necessarily of roller form) could occur downstream of the weir crest. Normally when free-discharge conditions operated, drawdown occurred at the end of the crest and the flow was supercritical. The limiting condition was reached when the Froude number of the flow at the end of the crest just upstream of the jump was unity, i.e. there was no drawdown; any further rise in the tail-water would produce subcritical flow conditions on the crest and would influence the water level upstream of the weir. The submergence limit would be a function of relative weir height $P / d$ and would therefore not have a constant value.

113. The momentum theory had been applied to this problem by Mr Ackers and Mr Harrison, assuming the pressure on the back face of the weir to vary uniformly along its height from $w d$ to $w y$ (where $y$ was the tail-water depth and $w$ was the specific 
weight of water) but neglecting boundary layer effects on the crest. Defining the submergence ratio as:

$$
\begin{aligned}
S & =\frac{\text { Tail-water level above crest }}{\text { Energy level on crest }} \\
& =\frac{y-P}{3 d / 2},
\end{aligned}
$$

$S$ could be shown to vary from 0.667 at $P / d=0$ to a maximum of 0.89 at $P / d=0.667$ returning 0.667 at $P / d=\infty$. For the practical range of $P / d$ values from 0.2 to 9 , this momentum analysis showed that $S$ varied from 0.83 through 0.89 to 0.78 .

114. In $\$ \S 36$ to 40 the Author argued against the use of a rounded entry because of the alleged difficulties in theoretical calibration. Mr Ackers and $\mathrm{Mr}$ Harrison disagreed with these arguments, however, and believed that a streamlined broadcrested weir was in fact a more practical design for the following reasons:

(a) The round-entry weir was more able to pass sediment and floating trash without damage, and the coefficient was not sensitive to deposits of sediment occurring just upstream, as was the coefficient of a sharp-entry weir.

(b) The round-entry weir was not as sensitive as was the sharp-entry weir to slight changes in direction of the approach velocity.

(c) Any damage to the square corner of a rectangular profile weir would effectively blunt the corner, which would have a major influence on the size of the separation bubble and hence on the coefficient.

(d) The head losses on the crest were smaller and, consequently, assuming it was possible to assess these losses no less accurately than in the sharp entry case, the overall accuracy with which the weir coefficient could be determined was improved.

115. The Author suggested that the boundary layer transition made the location of the critical section upon a rounded broad-crest weir uncertain. However, in a practical case when the crest length $L$ might be about $8 \mathrm{ft}$, the transition from laminar to turbulent boundary layer flow occurred relatively close to the upstream end of the crest, and, since $\delta^{*}$ grew more rapidly in a turbulent layer than in a laminar layer, the value of $\delta^{*}$ (turbulent) at the downstream end of the crest would be greater than $\delta^{*}$ (laminar) at the transition so that the hypothecated transition point throat would be drowned out by downstream control. Furthermore there was not a $50 \%$ reduction in $\delta^{*}$ at the transition point as suggested by the Author because the transition from laminar to turbulent conditions was gradual and occupied a considerable distance; the reduction, if any, was only small. This was demonstrated by Dhawan and Narasimha ${ }^{42}$ who showed that $\delta^{*}$ did not decrease at all through the transition when the transition Reynolds number ( $U x_{\mathrm{t}} / \nu$ where $x_{\mathrm{t}}$ was the distance to the transition point) was less than about $4 \times 10^{5}$.

116. It was clear that there was room for a good deal of additional thought and experiment on broad-crested weirs of both sharp and round entry. For example, no account had been taken in the theoretical analyses of the longitudinal pressure gradient on the boundary layer or of the drawdown region at the end of the crest, and accurate calibration data were required in support of the latest methods. Velocity profile and pressure measurements would also be useful. $\mathrm{Mr}$ Ackers and $\mathrm{Mr}$ Harrison found that with certain assumptions in these respects the momentum theory could be applied to flow over a sharp-entry broad-crested weir, which, taking account of the boundary layer, agreed with Bazin's data to within $2 \%$. The theory automatically allowed for the weir height factor and might be developed further if some experimental confirmation of the assumptions involved in the method were provided.

117. The Author concluded with a general criticism of a paper by Mr Ackers. ${ }^{12}$ A more careful consideration of that paper would have shown that its intention was to extend a known method of obtaining theoretically the calibration of a streamlined 
critical-depth meter to cross-sectional shapes other than the simple rectangle. The limitations of that method, which assumed that the friction loss in the throat would not be far removed from that which would occur under normal uniform flow conditions, were fully appreciated, and the reader's attention was drawn to this point. In fact, there was relatively little difference in magnitude between the boundary layer friction assessment and the uniform flow value, the influence on the overall coefficient being well within the tolerance expected in gauging installations and also below the tolerances involved in experimental studies as yet published.

118. The Author's concept of flow, as illustrated in Fig. 1a, indicated a boundary layer increasing in thickness from that given by the height of the separation bubble. Surely this implied that the main streamlines were horizontal above the separation zone, whereas experiments indicated a general downward component in the main flow just beyond the crest of this zone. Furthermore, in Fig. $1 a, \delta$, the full boundary layer thickness, was shown as increasing from an initial value defined by $0 \cdot 109 \mathrm{H}$, whereas in Fig. 1b and the text of the Paper, it was $\delta^{*}$, the displacement thickness of the boundary layer, which was assumed to have an initial value of $0 \cdot 109 H$. Using the $\frac{1}{7}$ th power law velocity distribution, $\delta=8 \delta^{*}$. Thus if $\delta_{0}^{*}=0 \cdot 109 H, \delta$ must exceed $0.87 \mathrm{H}$; the Author's suggested model for flow. over a rectangular-crested weir implied a boundary layer thickness in excess of the depth of flow. This was impossible, of course, and it followed that the assumed value of $\delta_{0}^{*}$ was not consistent with the concept of a developing boundary layer. Hence it could also be said of the Author's conceptual model that it implied a fully-developed velocity profile throughout the depth of the fluid!

Mr Herbert Addison (Consultant) considered that there was most encouraging agreement between the Author's analytical results and those obtained by experiment. Researchers who wished to extend the scope of the enquiry might be deterred, however, by the Author's strictures in $\$ 53$, where he expressed his anxiety to discourage waste of effort and expense in uncontributive experimentation. What kind of experiments would the Author regard as fruitful? There were hints in various parts of the Paper. $\$ 47$ referred to the lack of experimental results concerning the effect of side walls, while $\$ 50$ deplored a lack of systematic experimental tesults which would check the validity of relevant suppositions. Would it be permissible to try to fill these gaps?

120. Again, would it be profitable to determine experimentally the shape of the velocity distribution curve sketched in Fig. 1a, in order that the true thickness $\delta$ of the boundary layer could be assessed? This diagram included a term that might be thought misleading - the term 'separation bubble' to denote the recirculation region near the crest inlet edge. If this use of the word 'bubble' should be generally accepted, it might create serious confusion. Such a 'bubble' - an annular one--existed near the sharp-edged inlet to a circular pipe; yet other kinds of bubble-real bubbles-might also be found here. If the absolute pressure were low enough, cavitation bubbles of air or vapour would be released. Would it not be better, then, to use the word 'bubble' only in its generally-accepted sense, as implying something globular and possibly fugitive or fragile? As for the recirculatory region which was not spherical and was not in the least fragile, why not call it 'flat vortex' or 'annular vortex' as the case might be?

121. There seemed to be a little inconsistency between $\S 2$ and $\S 49$. Since one of the aims of the Paper was to assist in formulating recommendations for openchannel flow-measurement, why was it necessary to reject all comment on the comparative advantages of different forms of flow-measuring structure? Such discussion would at least show in which direction future analysis would be most useful.

Mr W. K. Allan and Mr J. M. Williams (Applied Mechanics Branch, Royal Military College of Science) considered that Dr Hall was to be supported in his 
endeavour to introduce the concepts of boundary layer theory into the field of hydraulic flow. This approach promised a greater understanding of the phenomena involved than had been obtained hitherto, an understanding that might be capable of wider application. Inevitably some simplification of the real flow system was necessary if undue complexity was to be avoided. In the simplified flow model, however, care must be taken to avoid over-simplification, and the limitations imposed by legitimate approximations must be appreciated.

123. The Author suggested, as the basis of Ippen's relationship for discharge coefficient, equation (1), a flow model which represented the effects of viscous stresses as a contraction of flow area only. The following analysis, however, suggested that Ippen's equation should be interpreted as an approximation to the solution of a flow model involving momentum and energy losses as well as effective displacement of solid boundaries. Further, an attempt would be made to estimate the magnitude of the error involved in this approximation, and to investigate the range of application of the flow model.

\section{Critical flow with friction}

124. Considering the two-dimensional flow of an incompressible, viscous liquid in an open channel, such that at any section the velocity profile included a constant velocity, $U_{0}$, portion, then, if the depth of flow be denoted by $h$, the volume discharge per unit width of channel would be

$$
q=U_{0}\left(h-\delta^{*}\right),
$$

where $\delta^{*}$ was the boundary layer displacement thickness. Further, the total kinetic energy of the stream at that section would be given by

$$
K . E .=\frac{1}{2} \rho U_{0}^{2}\left(q-U_{0} \delta^{* *}\right),
$$

where $\delta^{* *}$ was the boundary layer energy thickness at that section.

125. If now a hydrostatic variation of static pressure with depth was assumed, then the specific energy, $E$, of the stream could be written

$$
\begin{aligned}
E & =\begin{array}{c}
\text { total energy per pound of fluid, reckoned above } \\
\text { channel bed level, }
\end{array} \\
& =h+\frac{1}{2} h_{\mathrm{c}_{0}}^{3} \frac{\left(h-\delta^{*}-\delta^{*}\right)}{\left(h-\delta^{*}\right)^{3}}, \text {. . . . . . . . . }
\end{aligned}
$$

where

$$
h_{\mathrm{c}_{0}}=\sqrt[3]{q^{2} / g} .
$$

126. At any section, local characteristics of the boundary layer might be taken to be independent of the local parameters of the flow system, such as the local depth, $h$, but dependent upon the previous history of the layer. Thus it could be shown that at a section where the specific energy became a minimum, i.e. for critical flow, the corresponding depth of flow, the critical depth, $h_{\mathrm{o}}$ would be given by

$$
h_{\mathrm{c}}=h_{\mathrm{c}_{\mathrm{o}}} \sqrt[3]{\frac{1-\left(\delta^{*} / h_{\mathrm{c}}\right)-(3 / 2)\left(\delta^{* *} / h_{\mathrm{c}}\right)}{\left[1-\left(\delta^{*} / h_{\mathrm{c}}\right)\right]^{4}}} .
$$

\section{Broad-crested weir}

127. Considering the case of the flow of a viscous liquid over a broad-crested weir having a horizontal crest, such that critical flow was achieved at the downstream edge of the weir, then the total head of the stream at that section, reckoned above weir crest level, would be given by

$$
E_{\min }=h_{\mathrm{c}}\left\{1+\frac{1}{2}\left(1-\delta^{*} / h_{\mathrm{c}}\right)\left[\frac{h_{\mathrm{c}}-\delta^{*}-\delta^{* *}}{h_{\mathrm{c}}-\delta^{*}-(3 / 2) \delta^{* *}}\right]\right\} .
$$

128. If at some section well upstream of the weir the flow velocity might be taken to be very small, then the total head of the stream at that section would be given by 
the height of the surface above the weir crest level, $H$. The head lost in the flow between these sections could be related to the momentum thickness of the boundary layer, $\theta$, at the downstream edge of the weir. Assuming that the acceleration of the flow due to the fall of surface level along the crest was small, then the head lost would be given by

$$
H-E_{\mathrm{min}}=\frac{\theta U_{0}^{2}}{h_{\mathrm{c} g}}=\frac{\theta h_{\mathrm{c}_{\mathrm{o}}}^{\mathrm{3}}}{h_{\mathrm{c}}\left(h_{\mathrm{o}}-\bar{\delta}^{*}\right)^{2}} .
$$

129. This equation could be solved for the depth ratio $\left(h_{\mathrm{c}} / H\right)$ to give

$$
\frac{h_{\mathrm{c}}}{H}=\frac{x}{x+y+z}
$$

where

$$
\begin{aligned}
& x=1-\left(\delta^{*} / h_{\mathrm{c}}\right)-(3 / 2)\left(\delta^{* *} / h_{\mathrm{c}}\right), \\
& y=\left(\theta / h_{\mathrm{c}}\right)\left(1-\delta^{*} / h_{\mathrm{c}}\right)^{2},
\end{aligned}
$$

and

$$
z=\frac{1}{2}\left(1-\delta^{*} / h_{\mathrm{c}}\right)\left[1-\left(\delta^{*} / h_{\mathrm{c}}\right)-\delta^{* *} / h_{\mathrm{c}}\right] \text {. }
$$

130. Then, since the discharge coefficient, $C$, was given by

$$
C=\frac{q}{(2 / 3)^{3 / 2} g^{1 / 2} H^{3 / 2}}=\left[(3 / 2)\left(h_{\mathrm{co}} / H\right)\right]^{3 / 2}, \quad \text {. . . . }
$$

the problem might be solved if the boundary layer thicknesses could be estimated.

131. These equations could be simplified for comparison with Ippen's equation by the assumption of a $\frac{1}{7}$ th power law velocity profile at the downstream edge of the weir. Then the depth ratios $\left(h_{\mathrm{c}} / h_{\mathrm{c}_{\mathrm{o}}}\right)$ and $\left(h_{\mathrm{c}} / H\right)$, and the discharge coefficient, $C$, could be expressed as functions of the displacement ratio, $\left(\delta^{*} / H\right)$. Further, reducing the solution to the first order of magnitude, it might be shown that, approximately,

$$
C=\left[1-1 \cdot 08\left(\delta^{*} / H\right)\right]^{3 / 2} \text {, }
$$

which compared very agreeably with Ippen's equation.

132. It was pertinent at this point to evaluate the range of application of the present analysis. It was suggested that the concept of the boundary layer, and therefore the definitions of the various thicknesses, could no longer be applied when the flow velocity varied throughout the whole of the depth of flow. For a $\frac{1}{7}$ th power velocity-profile this would occur when $\delta^{*} / h_{\mathrm{o}} \geqslant 0 \cdot 125$, or, from the present analysis, when

$$
\delta^{*} / H \geqslant 0.077 \text { or } C \leqslant 0.87 \text {. }
$$

It must be noted that this was a theoretical limitation and that in practice the discharge coefficient equation might continue to be of value beyond this limit.

133. In the range of $0.87 \leqslant C \leqslant 1.00$, values of discharge coefficient predicted by the present analysis were found to be less than $2 \%$ lower than those predicted by Ippen's equation.

\section{Conclusions}

134. Within the limits of the assumptions of the present analysis, it had been shown that Ippen's equation was a reasonable approximation for the discharge coefficient of a broad-crested weir in two-dimensional flow. The present solution also suggested a means of calculating the depth ratios.

135. Further, it was suggested that for $C \leqslant 0.87$ the flow at the downstream edge of the weir would be 'fully developed'. The present analysis would then cease to apply.

Mr K. J. Zanker (British Hydromechanics Research Association, Harlow) wrote that the major cause of the discharge coefficient $C$ deviating from unity was the assumed height of the separation bubble. As soon as $\delta_{0}^{*} / H=0 \cdot 109$ was chosen one had $C \ngtr 0.84$ accounting for a $16 \%$ deviation of $C$ from unity. The subsequent 
growth of the boundary layer on the crest was a relatively small effect, reducing $C$ by $1 \%$ in a crest length of $6 H$.

137. No theoretical arguments, analyses or boundary layer theory seemed to have entered into the arbitrary choice of $\delta_{0}^{*} / H=0.109$. In the Appendix the Author had suggested that there was similarity between the three flows shown in Fig. 8, i.e.

$$
\frac{\delta_{0}^{*}}{H}=\frac{x}{H^{\prime}}=\frac{y}{D} \text {. }
$$

138. The boundary conditions of these flows obviously differed and the flows themselves were not similar. Surely if any similarity between the orifice and broadcrested weir was assumed, it would be more reasonable to guess that

$$
\frac{\delta_{0}^{*}}{h}=\frac{y}{D / 2} \quad \text { giving } \quad \frac{\delta_{0}^{*}}{H}=2\left(\frac{h}{H}\right)\left(\frac{y}{D}\right)=\frac{4}{3}\left(\frac{y}{D}\right)=0.145 \text {. }
$$

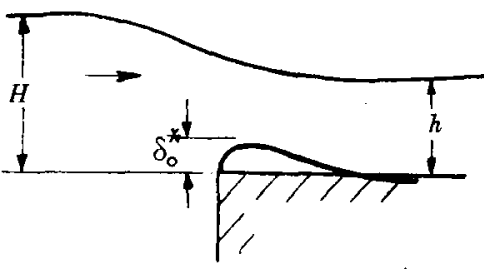

BROAD CRESTED WEIR

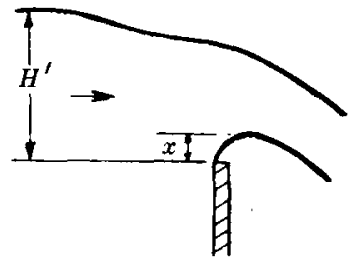

SQUARE EDGE THIN PLATE WEIR

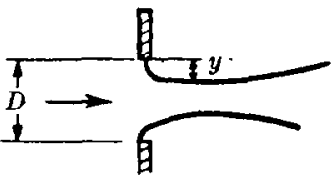

ORIFICE

FIG, 8
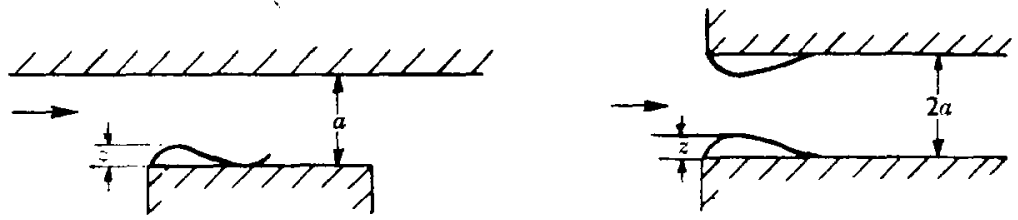

Fig. 9

139. The two flows shown in Fig. 9 had at least similar boundary conditions on the one side where the contraction occurred, in distinction to the two cited above by the Author where the contraction was free. For both these cases the discharge coefficient extrapolated to zero length was $C_{\mathrm{d}}=0.835$ which could be accounted for by a sudden expansion loss with $C_{c}=0.61$ giving $(a-z) / a=\sqrt{0.61}$ or $z / a=0.22$. Again any similarity with the Author's case would suggest that

$$
\frac{\delta_{0}^{*}}{h}=\frac{z}{a} \text { i.e. } \frac{\delta_{0}^{*}}{H}=\frac{2}{3}\left(\frac{z}{a}\right)=0 \cdot 147 .
$$

140. It seemed difficult to justify the Author's assumption that $\delta_{0}^{*} / H=0 \cdot 109$ on any other grounds than that his final $C$ values agreed well with experiment. 
141. Considering the importance of the numerical value of $\delta_{0}^{*} / H$ to the whole Paper more information on the nature and geometry of the separation bubble would seem desirable.

Dr F. V. A. Engel (Consultant) and Mr W. Stainsby (Technical Department, Elliott Process Automation Ltd) considered that the importance of Dr Hall's theoretical approach to problems related to broad-crested weirs should not be underestimated. His Paper deserved a careful study as it stimulated interest in a common type of weir which had not been sufficiently investigated.

143. However, two investigations by C. Keutner ${ }^{43}$ and H. Bretschneider ${ }^{44}$ showed that a different interpretation of the discharge coefficient characteristics could be given.

144. It was of interest to note that Keutner referred to the dimensions of the separation zone (bubble). Keutner gave its approximate height equal to $0 \cdot 15 \mathrm{~h}$ and its length to about $0.77 \mathrm{~h}$. No further conclusions were drawn from these observations and no attempt was made to correlate this phenomenon with the theoretical contraction coefficient which, more recently, had been carefully studied in connexion with square-edged, thin-plate weirs. ${ }^{45}$

145. The thesis by $\mathbf{H}$. Bretschneider, ${ }^{44}$ the latest experimental publication on broad-crested weirs, afforded an example of a different explanation of viscosity influences. First of all, it showed that the ranges of constant discharge coefficients and variable discharge coefficients were characterized respectively by continuouslydownwards sloping water level above the weir crest or the occurrence of a standing wave, shown in Fig. 10.

146. Fig. 11 was mainly concerned with the variation of the discharge coefficient in the flow regime determined by standing waves. The major range of the constant discharge coefficient extending to $h / w=1$ was omitted.

147. The standing wave was a particular type of hydraulic jump, namely, the undular jump. It was related to low Froude numbers close to 1 .

148. From recent investigations on the various types of hydraulic jumps it was apparent that a special phenomenon related to the undular jump was not sufficiently known. J. Einwachter ${ }^{46,47}$ had shown that underneath the wave crests a roller, like a 'separation' zone, was observed on the horizontal channel invert illustrated in Fig. 12.

149. Dr Engel and Mr Stainsby enquired whether this 'separation' zone coincided with the 'contraction' zone of broad-crested weirs; were these phenomena superimposed, or did the 'contraction' zone replace the 'separation' zone? These were open questions which should be considered in future experimental investigations, as they were related to the range of the variable discharge coefficient. This meant that other influencing factors existed and it appeared doubtful if boundary layer theory could give an exhaustive explanation of the discharge characteristics illustrated in Fig. 11.

150. Bretschneider stated that the location where the critical depth occurred was downstream of the standing wave. The fact that the Froude number was close to $i$ for the standing wave type and neglecting separation or contraction zones, and a boundary or displacement layer might explain his statement. A standing wave could only occur if the critical depth had been reached upstream of the first wave in the array of waves. Accordingly, Fig. 10 showed tentatively the locus of critical depths.

151. Reverting to Fig. 11, it became evident that the boundary layer relations established by Dr Hall were at least an over-simplification. Other influencing factors and phenomena determined shape and slope of the discharge coefficient characteristics in the ranges of low Froude numbers and low Reynolds numbers. In the case of convergent flow filaments the range of low Reynolds numbers might cover values between 50000 and approximately 200000 . 


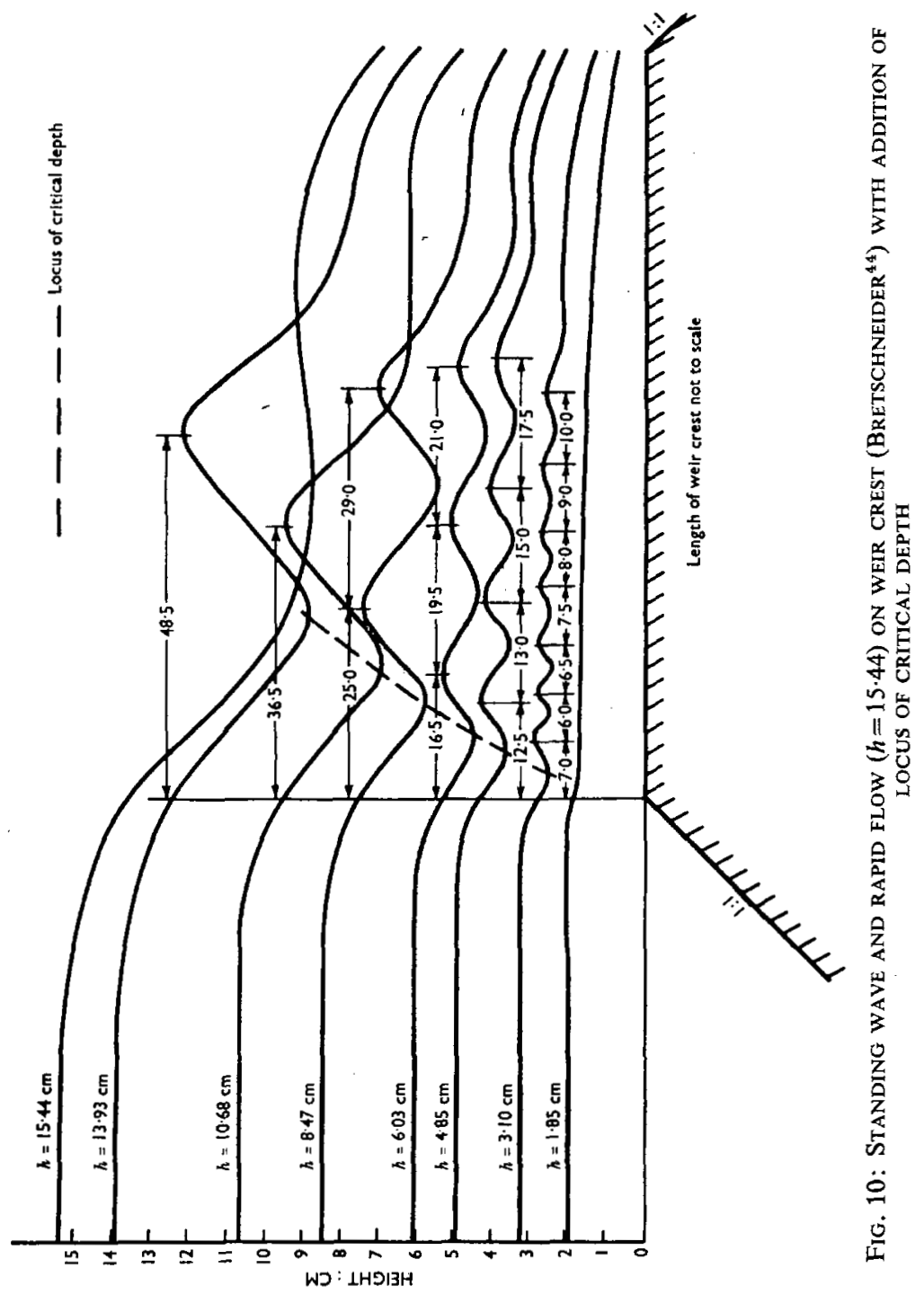




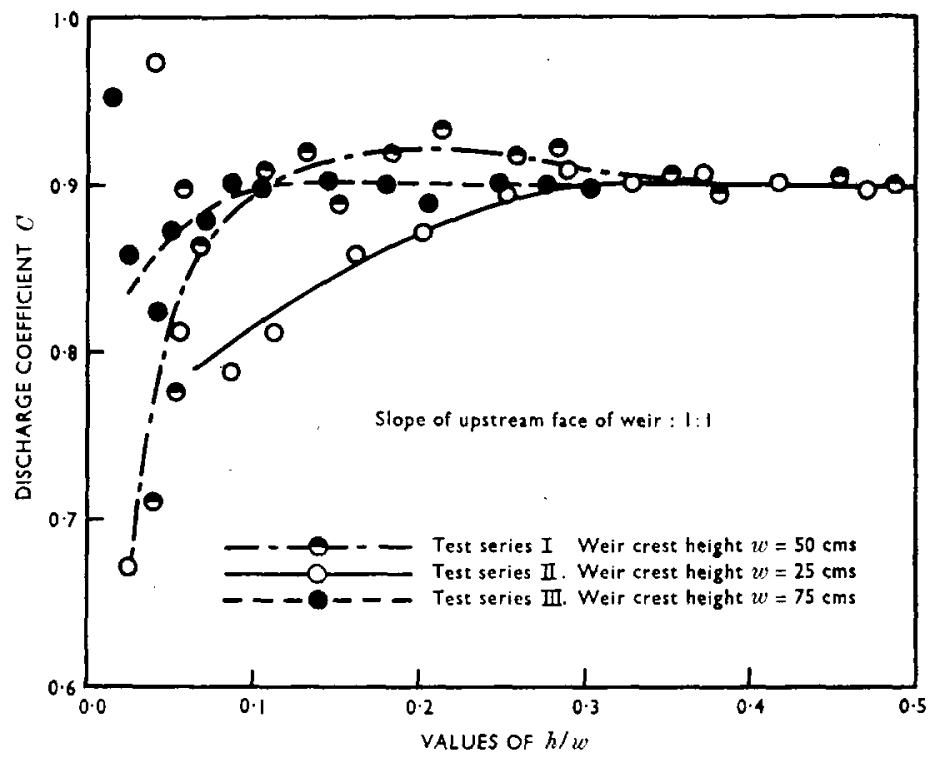

(a) Slope of upstream face of weir: 1:1

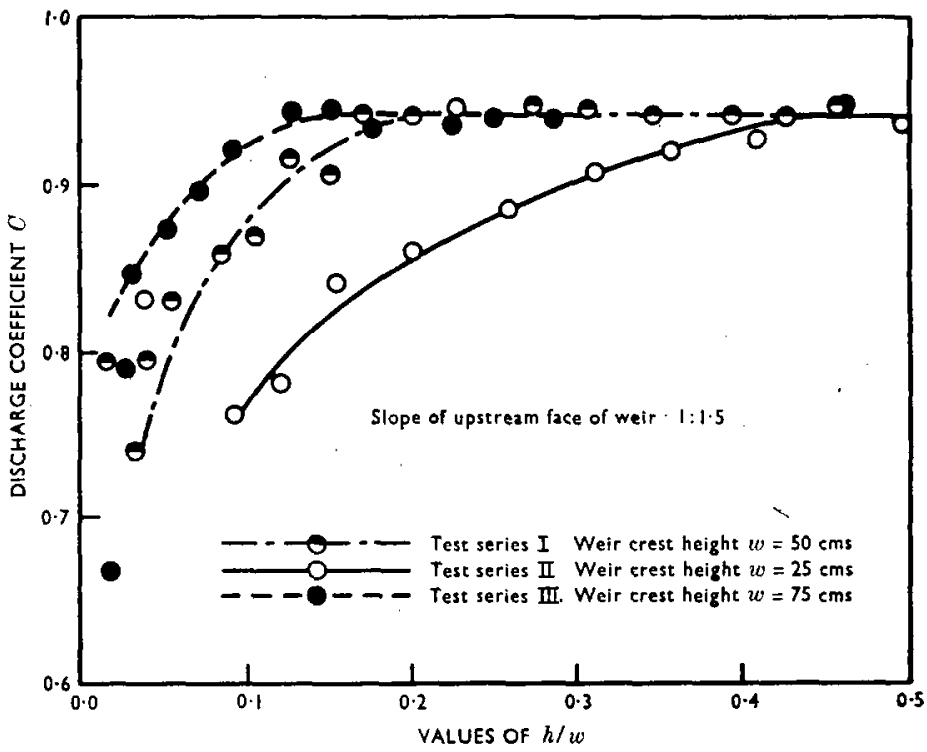

(b) Slope of upstream face of weir: $1: 1 \cdot 5$

Fig. 11: Discharge CoefFicient versus Ratio/Height OF Weir CREST ABOVE CHANNEL INVERT, i.e. A MODIFIED DEPTH RATIO (BRETSCHNEIDER ${ }^{44}$ ) 
152. In accordance with Bretschneider the term $h / w$ had been chosen for the abscissa values. The area ratio $h /(h+w)$ and the term $h / w$ were related as follows:

$$
\frac{h}{w}=\frac{h /(h+w)}{1-\bar{h} /(h+w)}
$$

The Reynolds number should have been chosen for plotting the curves, but, unfortunately, temperatures were not given in the otherwise comprehensive tables of Bretschneider's thesis. For a better understanding of peculiarities in the discharge characteristics, temperature ranges were given in Table 5 which were kindly communicated to Dr Engel by Dr Bretschneider.

Table 5: Temperature Ranges in ${ }^{\circ} \mathrm{C}$

\begin{tabular}{c|c|c|c}
\hline $\begin{array}{c}\text { Slope of } \\
\text { upstream } \\
\text { weir face }\end{array}$ & $\begin{array}{c}\text { Test Series I } \\
\text { weir height, } \\
w=50 \mathrm{~cm}\end{array}$ & $\begin{array}{c}\text { Test Series II } \\
\text { weir height, } \\
w=25 \mathrm{~cm}\end{array}$ & $\begin{array}{c}\text { Test Series III } \\
\text { weir height, } \\
w=75 \mathrm{~cm}\end{array}$ \\
\hline $1: 1$ & $\begin{array}{c}15-17 \cdot 2^{\circ} \\
1: 1 \cdot 5\end{array}$ & $\begin{array}{c}16 \cdot 6-17 \cdot 4^{\circ} \\
17 \cdot 6-18 \cdot 6^{\circ}\end{array}$ & $\begin{array}{c}18 \cdot 8-19 \cdot 8^{\circ} \\
19 \cdot 0-20 \cdot 4^{\circ}\end{array}$ \\
$\begin{array}{c}15 \cdot 4-17 \cdot 2^{\circ} \\
1: 2\end{array}$ & $\begin{array}{l}15 \cdot 6-12^{\circ} \\
16 \cdot 8-18^{\circ}\end{array}$ \\
\hline
\end{tabular}

153. From Fig. 11, it was evident that besides the temperature ranges as specified in Table 5, weir height and the sloping angle of the upstream weir face were essential factors.

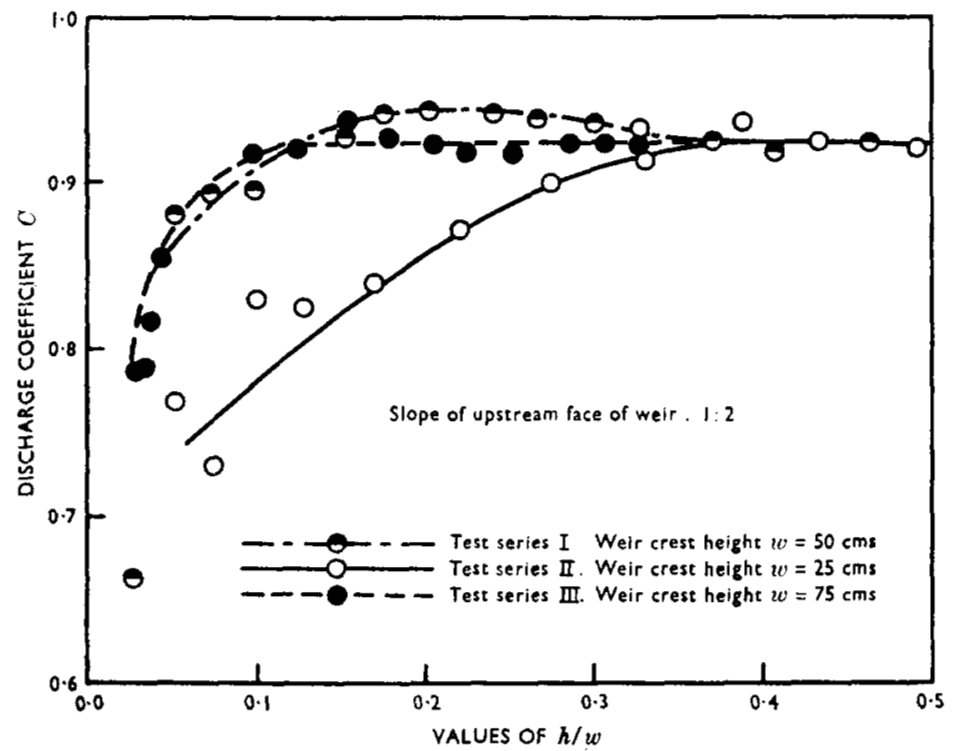

(c) Slope of upstream face of weir: $1: 2$

FIG. 11-continued 


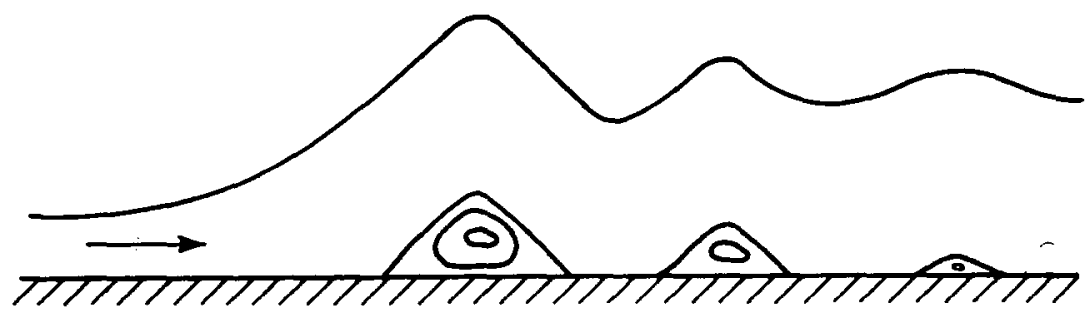

Fig. 12: STANDING WAVE, UNDULAR-TYPE JUMP WITH ROLLERS ON CHANNEL FLOOR UNDERNEATH WAVE CREST (Einwachter ${ }^{46-17}$ )

154. The curves for Series II, with the lowest crest, and for Series III, with the highest, showed distinct characteristics. They might be due to the approach conditions. If the available approach length of the entrance channel, which in all cases was the same, i.e. approximately 10 to $12 \mathrm{~m}$, was related to the weir height, it became evident that upstream conditions for Series II were three times as favourable in comparison with Series III. Series II, with its greater relative approach length, was characterized by a low disturbance level and a more evenly-developed velocity profile. This explained the gentle slope of all the curves of Series II, which merged steadily into that part of the discharge characteristic which represented a constant coefficient. The Reynolds number indicating the beginning of the constant coefficient and the breakdown of marked viscous influences was shifted to higher Reynolds numbers (in Fig. 11, expressed by higher $h / w$-values). In contrast the test runs of Series III were subject to a high disturbance level and an insufficiently-developed velocity profile. Therefore, in Series III an extended 'constancy' range existed; the steeply sloping curves merged into the constant coefficient characteristic at low $h / w$-values (lower Reynolds numbers). Temperature influences were superimposed on all discharge curves. This fact was shown pronounced by the hump in the discharge curves in Figs $11 \mathrm{a}$ and $11 \mathrm{c}$ for two sets of Series I with the low temperature ranges (see Table 5).

155. Furthermore, relative roughness might explain the various characteristics shown in Fig. 11. With decreasing heads, $h$, the relative roughness might increase considerably. It should be noted that Bretschneider used concrete slabs for his weir structure. The overall length of the converging entrance section, i.e. the upwards slope of the weir face, depended on the weir height, $w$, as well as on the sloping angle. The shortest length of contact of the water stream with the weir face existed in Series I, which showed the steadily increasing coefficient curve extended to high Reynolds numbers (high $h / w$-values up to 0.42 !). Test Series III had the greatest contact surface and accordingly, due to roughness disturbances, the breakdown of viscous influences commenced at low Reynolds numbers, i.e. low $h / w$-values of about $0 \cdot 1$. Both temperature and roughness influences might produce similar results on the trend of the coefficient curves.

156. With respect to roughness influences it might be necessary to qualify $\S 41$ in the Paper. The considerations of roughness influences outlined in the previous paragraph were not applicable to the relative roughness of the weir crest. C. Keutner ${ }^{43}$ had shown that the discharge coefficient was not altered in the 'constancy" range even by a considerable roughness of the weir crest. The constancy range was given approximately by $h / w>0.32$, which was well in line with the beginning of the constancy range shown in Fig. 11. Indentations, of trapezoidal cross section, $2.5 \mathrm{~cm}$ deep and spaced at about $3 \mathrm{~cm}$ covering the total length of the weir crest, resulted merely in a change of the flow pattern. Normal fiow conditions and a smooth surface of the weir crest resulted in rapid flow with a continuous drop of the water level along the weir crest, whilst the rough surface produced a standing wave 
with a crest of the wave about $30 \%$ above the critical depth. This phenomenon might be a special case or a limiting case where the discharge coefficient was not yet influenced as pointed out previously with reference to Fig. 10 where the undular jump characterized variable discharge coefficients.

157. A simplified equation and an explanation of the 'constancy' range of the discharge coefficient had been dealt with by Dr Engel and Mr Stainsby in a publication on 'Broad-crested weirs'. ${ }^{48}$

Mr Gerald Lacey (Consultant, Sir Murdoch Macdonald and Partners) remarked that the Author had sought by the application of the boundary layer theory to determine the discharge characteristics of broad-crested weirs. This subject was of great interest to all engineers responsible for the design or operation of weirs, for many such works approximated to the long-structured type and therefore could also be made to serve the purpose of a metering device.

159. The broad-crested weir was chosen by the Author for investigation primarily on the grounds of its relative simplicity and the availability of experimental data. $\mathrm{He}$ had facilitated the solution of his two-dimensional problem by adopting a square entry-edge and drew attention to the awkward fact that a radiused crest-entry-edge added considerably to the problem of analysis in so far as geometrical similarity of the entrance boundary contour was no longer preserved.

160. From the viewpoint of international standard methods of measuring relatively small discharges there was much to be said for the employment of every simplification which allowed the research worker to make a rigid analysis. The irrigation engineer had no such inhibitions for, in the same way that Nature abhorred a vacuum, he had acquired a marked dislike for square-edged entries either for bridge abutments or weir crests and preferred to put his faith in stream-lining. For these reasons the engineer was more interested in the problem of employing existing weirs as metering devices and in ascertaining the extent to which empirical gauge-discharge relationships were supported by rational analytical means than in a formal squareedged broad-crested weir. In practice bell-mouthed entries went far to minimize side-wall influence, and rounded upstream edges of the crest went far to suppress the separation bubble shown in Fig. 1a. Indeed the bubble was a direct result of the adoption of a profile which lent itself to theoretical analysis but which was nevertheless repugnant to the engineer.

161. It was noted that $H$ was defined as the upstream total head above the weir crest whereas, in Fig. 1, $H$ extended only to water surface level. If the approach walls were spaced a distance, $B$, apart, the depth of flowing water at the gauge site would be $G+P$ in which $G$ was the gauge. Hence for any value of $q$, the unit discharge, the mean velocity of approach $V_{\mathrm{a}}$ would equal $q /(G+P)$. This allowed the

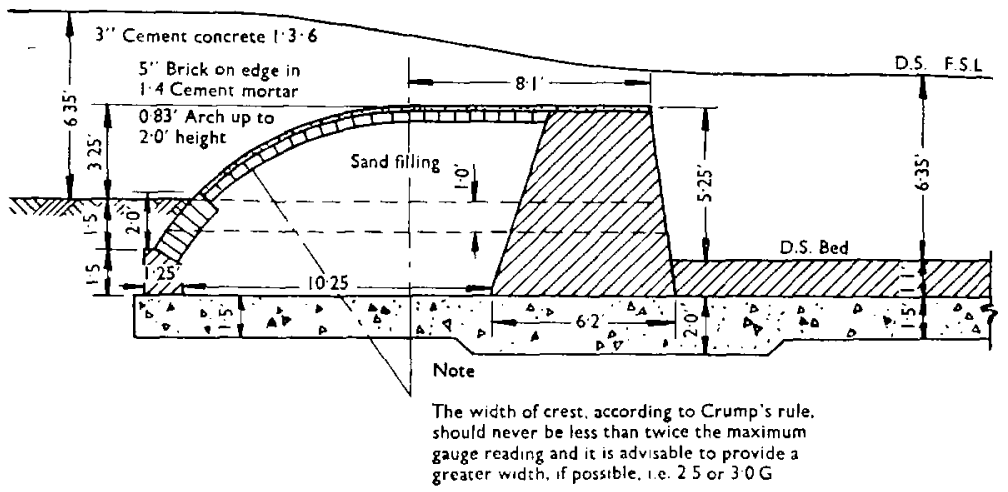

FIG. 13 
velocity head and finally $H$, the height of the total energy line, to be determined. Not only did the value of $P$ affect the height of the total energy line, which was basic to the entire analysis, but it had also a marked effect on the flow net upstream.

162. In Fig. 13 was shown a profile which Mr Lacey adopted some 30 years ago ${ }^{49}$ when remodelling a fall on the Sarda Canal in order to employ it as a metering device. The ratio $P / H$ was approximately unity. What was noteworthy was the very large radius of the rounded upstream crest. To a great extent this obviated the objection to a rounded crest of small radius. The gauge was read in a well situated in a quadrant bell-mouthed entry and so corresponded very closely to the true height of the total energy line. The meter was calibrated by a series of current meter observations made with great care and the gauge-discharge equation departed very little from the ideal flow rate.

163. With large weirs also, in which the profiles did not strictly conform with an ideal broad-crested weir, the empirical equations in terms of the gauge $G$ could be transformed into the ideal expression,

$$
q=(2 / 3)^{1.5} g^{0.5} H^{1.5}
$$

if due allowance was made for the depression of the upstream bed level below the weir crest and for the velocity head. This opinion had long been held by Mr A. M. R. Montagu, M.I.C.E., based on his wide experience in the Punjab. Mr Lacey's present investigations only served to confirm Mr Montagu's views.

164. It was of interest to examine the empirical gauge-discharge relationship derived for the Diyala Weir, Iraq, as reconstructed, ${ }^{50}$ and to ascertain the extent to which it conformed with theory. In the following analysis the value of $P$ was assumed as $1 \mathrm{~m}$. When computing the velocity head many authorities (when employing foot-second units) adopted the expression $V^{2} / 50$ instead of $V^{2} / 64 \cdot 4$. In view of the high velocities and coarse bed material, Mr Lacey employed $V^{2} / 45$ or effectively

$$
h_{\mathrm{a}}=V_{\mathrm{a}}^{2} / 1 \cdot 4 g \text {. }
$$

165. The reconstructed weir had a vertical upstream face; the crest was rounded with a radius of $0.50 \mathrm{~m}$ and this was followed by a horizontal portion of $0.50 \mathrm{~m}$ and thereafter a $3: 1$ slope. The gauge discharge equation obtained from measured discharges was

$$
q=1 \cdot 90 G^{1 \cdot \mathbf{B}} .
$$

The ideal flow equation took the form

$$
q=1 \cdot 70 H^{1.5}=K H^{1.5}
$$

and in Table 6 the extent to which $K$ was, as a fact, a constant was ascertained.

TABLE 6

\begin{tabular}{c|c|c|c|c}
\hline$G$ & $(G+P)$ & $V_{\mathrm{a}}$ & $H$ & $K$ \\
\hline 2.000 & 3.000 & 1.920 & 2.268 & 1.686 \\
1.500 & 2.500 & 1.454 & 1.654 & 1.709 \\
1.000 & 2.000 & 0.950 & 1.066 & 1.727 \\
0.750 & 1.750 & 0.685 & 0.784 & 1.727 \\
0.500 & 1.500 & 0.418 & 0.513 & 1.707 \\
0.333 & 1.333 & 0.246 & 0.338 & 1.669 \\
\hline
\end{tabular}

166. It would be seen that over a large range of gauges the values of $K$ differed very little. The average value was $1 \cdot 70$ and this was fortuitous for if regard was paid to frictional losses the coefficient should have been smaller. What was important 
was the consistency and the small percentage error. Mr Lacey suggested that gaugedischarge equations for other existing weirs might well be examined with advantage.

167. The Author's reference to the empirical approach and its retarding effect on progress was somewhat obscure. The Paper might well represent a step towards a completely rational solution. As to possible waste of effort and expense in uncontributive experimentation, Mr Lacey firmly believed that progress was rarely made without mistakes and that there was no royal road which all must follow.

Mr J. Singer (Head of Fluid Dynamics Laboratory, Electroflo Meters Co. Ltd) and Mr J. R. Smith (Lecturer in Fluid Mechanics at Hendon Technical College) said that Dr Hall was to be congratulated on his stimulating approach to the assessment of the discharge characteristics of open channel measuring devices of the longstructure family and the attention which he had paid to the necessary extensions to his basic theory.

169. Before proceeding to further applications Mr Singer and Mr Smith would welcome a clarification of what appeared to be the fundamental assumptions.

170. In their opinion the central assumption of the analysis was the equality of the bubble height with the displacement thickness of the boundary layer at a certain point in the re-attachment region.

171. The Author identified the bubble height with the elevation of the nappe above the crest of a thin-plate weir. Such an analogy could only be valid if it was assumed that the contraction was independent of the boundary conditions downstream of the contraction and the conditions existing within the bubble, a plausible point really requiring experimental verification. Care should be taken when seeking further justification for this point from such sources as the work of von Mises on two-dimensional flow through a slot in the end of a channel. The case under consideration could not be obtained by splitting the two-dimensional flow down its axial plane of symmetry, for the constant pressure free-surface condition would not be realized along this plane.

172. Mr Singer and Mr Smith did not wish to overstress the importance of the exact value chosen for the bubble height since their own experiments tended to confirm a figure of about $0 \cdot 1 \mathrm{H}$. They were, however, more concerned with the fact that the boundary layer displacement thickness was chosen to coincide with this value-at what appeared to be an arbitrary point within the re-attachment region.

173. The physical model then used replaced the bubble and boundary layer structure by a continuous boundary layer which did not actually exist and thus might mask other important factors affecting the flow. Might it not be conceivable that the close agreement of the Author's theoretical coefficients and Bazin's experimental ones (a surprising choice for comparison) was possible only through the gearing of the displacement thickness to the bubble height? Such an approach could severely restrict the field of its application.

174. The latter point might perhaps be clarified by extending the present investigation to include the case of a sloping crest and in particular the case of a gently-sloping crest inclined at such an angle as would compensate for the boundary layer displacement thickness. This test would be of a special interest because the adoption of such a crest would conceivably result in an improvement of the 'efficiency' of performance of broad-crested weirs. Mr Singer and Mr Smith doubted whether such an improvement would occur in the case of a square-edge entry structure where the bubble height might exert an overriding influence; however, it would be more likely to occur with a rounded type of entry.

175. This led to the important question of assigning individual structures to a particular family. Thus Engel and Stainsby retained the sharp-edged broad-crested device in the weir group, whilst the Author's approach tended to set it apart. The fact that conditions existed for the re-attachment of the boundary layer did not need to imply that the boundary layer theory could be effectively used for prediction of 
discharge characteristics. Mr Singer and Mr Smith thought that such an approach offered good prospects of success in structures with rounded inlets, where the boundary layer extended all the way back to the entry-edge. Serious reservations, however, had to be made about the usefulness of such an approach in cases where the re-attachment of the boundary layer was interrupted by the elevation of the bottom of the stream above the crest.

Dr E. A. Bunt (Applied Physics Laboratory, Johns Hopkins University, Maryland, U.S.A.) wrote that it had been suggested that all problems in fluid mechanics were basically boundary layer ones. It seemed that Dr Hall's approach in choosing appropriate values of $\delta^{*} \max$ and then working back to show that the resulting coefficient of discharge was to all intents and purposes that actually obtained was a valuable contribution to the elucidation of one of the hydraulic problems listed by Rouse and Ince as calling urgently for analytical attack. ${ }^{51}$

177. Since the Paper dealt with open channel flow, it was suggested that a more satisfactory way of correlating results-and one, moreover, that was used, for example, by Bazin himself in expressing the velocity distribution in the vertical plane over a sloping weir would be in terms of the Froude number $F_{\mathrm{L}}$. A suitable expression was, in fact, implied by Dr Hall, namely,

$$
\frac{F_{\mathrm{L}}}{\sqrt{2}}=\frac{C}{\sqrt{3}}(H / L)^{0.5}
$$

its merit being that it gave the overall discharge coefficient at a glance, besides avoiding the necessity for reference to temperature, as when a Reynolds number was quoted (although, of course, it was still necessary to know the temperature if boundary layer thicknesses were to be calculated independently). It was thus felt pref able to say that $C$ was a function of $F_{\mathrm{L}}$ and $H / L$. (This really presupposed that the boundary layer flow was treated apart from the main inviscid flow.) $H^{\prime} / L$, a modified value of $H / L$, as given by Dr Hall's correction

$$
H^{\prime} / L=\left(H-\delta^{*}{ }_{\max }\right) / L,
$$

could be plotted in place of $H / L$, with $\delta^{*}{ }_{\max }$ conveniently obtained from his approximation in terms of the experimental discharge coefficient:

$$
\delta_{\max }^{*}=\frac{2}{3} H(1-C) \text {. }
$$

Bazin's data were replotted in this form in Fig. 14 (heavy line). This showed clearly how $C$ was reduced as $F_{\mathrm{L}}$ (and hence $R_{\mathrm{H}}$ ) increased, as suggested in the text. The choice of $0 \cdot 109 H$ for $\delta^{*}{ }_{\max }$ also recalled the amount of the empirical correction applied to the Francis weir flow formula to account for the flow defect arising from end contraction effects.

178. The progressive increase of discharge coefficient in Bazin's results also suggested the possibility of expressing the data in the form of an equation with fixed discharge coefficient by determining the position of an effective displacement surface from

$$
U_{\mathrm{t}}=C^{\prime} \sqrt{g(H-k)} .
$$

In order to accommodate the two values of $L$, the given head/quantity data were first plotted as $H / L$ versus $F_{\mathrm{L}}^{2}$ to give

$$
F_{\mathrm{L}}=0.697 \sqrt{(H / L)-0.0080}
$$

which was found to fit all points well except the last four for $L=6.56 \mathrm{ft}$ (which were also clearly out of step with Dr Hall's values of $C_{\mathrm{th}}$ ).

179. The effective reduction in the dimensionless head $H / L$ by the amount of 0.0080 to give $H^{\prime} / L$ in

$$
\frac{F_{\mathrm{L}}}{\sqrt{2}}=0.495\left(H^{\prime} / L\right)^{0.5}
$$




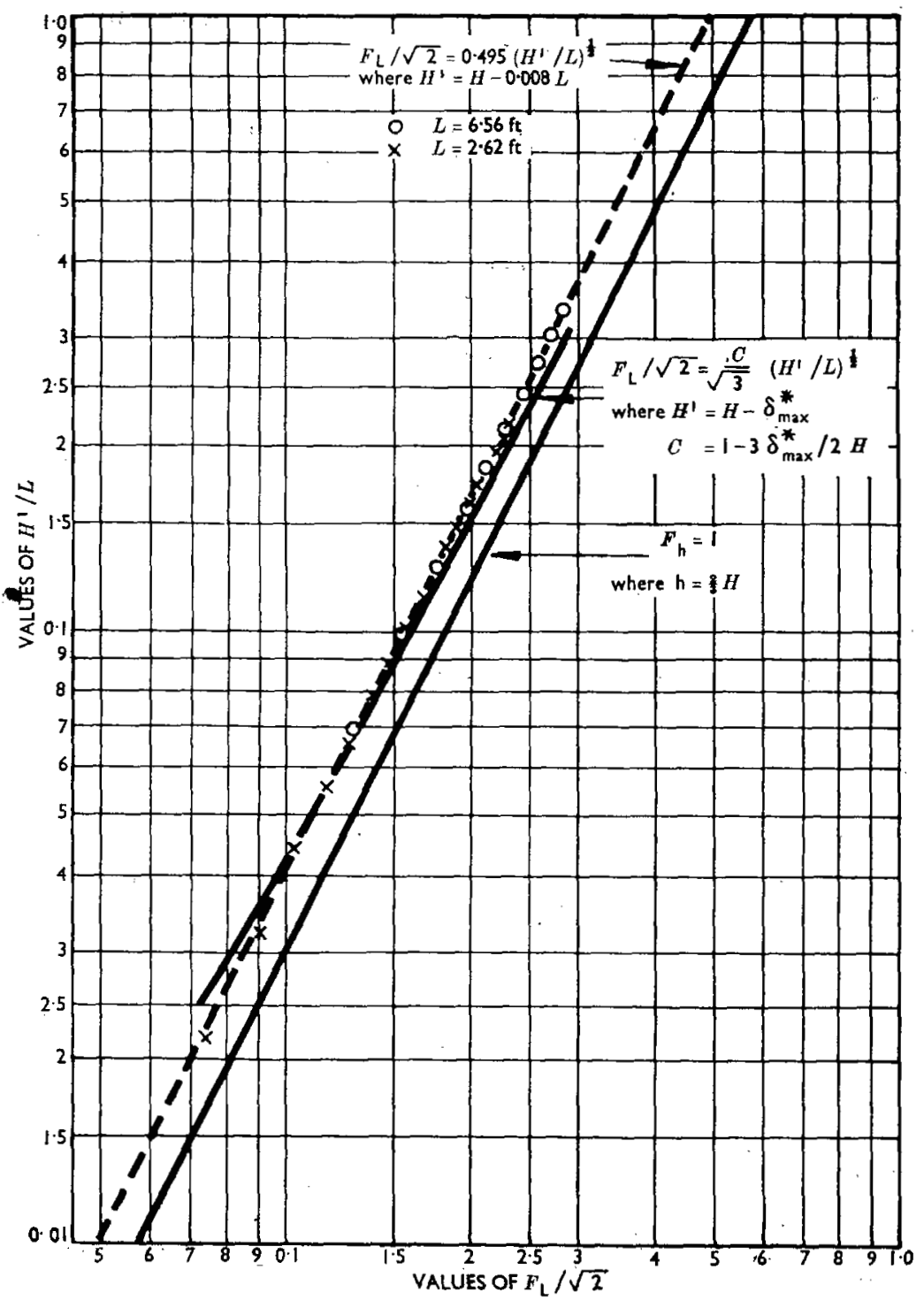

Fig. 14: GeNERALized Plot OF HEAD/Discharge OVER WeIR 
was also shown in Fig. 14. Since in ideal flow (for which $F_{h}=1$, where $h=\frac{2}{3} H$ ),

$$
\frac{F_{L}}{\sqrt{2}}=\frac{1}{\sqrt{3}}\left(H^{\prime} / L\right)^{0.5}
$$

the constant discharge coefficient was then $0.86(=0.495 \sqrt{3})$ - which was within the $10-15 \%$ range quoted as being necessary to account for losses in flow over broadcrested weirs. The absence of 'shock waves' on the surface should confirm the subcritical nature of this flow. Such a procedure could also be applied to modify Dr Hall's computed discharge coefficients if a further 'constant' value be desired within given limits. It might be expected that such an average $C$ would be closely related to the value of the head recovery ratio (submergence limit). This appeared to be the case.

180. Was experimental evidence available to confirm that the flow downstream of the effective hydraulic drop at boundary layer transition from laminar to turbulent was indeed supercritical? It was hoped to provide experimental evidence for equation (6) in due course.

181. Dr Hall's paper was a valuable continuation of his 1959 paper $^{52}$ with which it had much in common. It was a useful contribution to the welcome trend of bringing the methods and techniques of aerodynamics into the hydrodynamic field. It was certainly to be hoped that experimental observations of liquid boundary layers would be further extended.

The Author, in reply, wrote that he was most grateful to the contributors for their stimulating responses which collectively constituted an invaluable supplement to the Paper.

183. Repeated requests had been made for further enlightenment on the choice of theoretical model to represent the crest-entry bubble and its wake. An attempt to clarify that aspect was presented below.

184. First, two flows, both subject to gravity influence, were considered, namely, the free flow over a square-entry broad crest and the free nappe from a vertically disposed thin-plate weir. Two-dimensional conditions were presumed. The Author hypothesized that the relative dimensions of the nappe lower profile, at least as far as its maximum elevation, were identical in the two instances. The nappe profiles traced by Keutner ${ }^{43}$ in his Fig. 1 supported this plausible view. Suggestions had been made in the discussion that because the pressure within the bubble at entry to the broad crest differed from atmospheric pressure, the Author's hypothesis would be invalid. But the objection was unconvincing since, in the case of an orifice or slot, for example, the relative shapes of the free streamlines were manifestly independent of the differential pressure. Evidently, the only way to resolve the question would be by further experimentation.

185. Provided that the hypothesis discussed above was proved valid, then a value of $0.109 H$ for the bubble maximum elevation when $P \rightarrow \infty$ was a reasonable choice supported by many careful measurements.

186. Next to be examined was the extent to which the aforementioned basic dimension for the bubble maximum elevation needed to be modified to accommodate values of the parameter $H /(H+P)$ greater than zero. To effect such an estimate, the Author resorted to a quasi-empirical device which employed theoretical (von Mises/ Rouse) results relating to the flow through an orifice installed concentrically within a circular pipe. It was noticed that if the radial distance between the orifice jet at the vena-contracta and the orifice edge was expressed as a fraction of the orifice diameter, that ratio had the same numerical value as had been adopted for the weir entrybubble maximum elevation relative to the upstream total head, for the limiting values, zero and unity, of the 'area' ratios $d / D$ and $H /(H+P)$. The assumption was then made by the Author that identical values would occur also at the intermediate 'area' ratios. That presumption appeared reasonable since the streamlines for the two 
circumstances should be modified to an equivalent extent by the upstream wall proximity.

187. That this analytical device provided an acceptable result was demonstrated by Fig. 15 where the full line representing the Author's estimate of the nappe maximum elevation was contrasted with carefully executed experimental data $^{14}$ which were not available to the Author at the time the Paper was written.

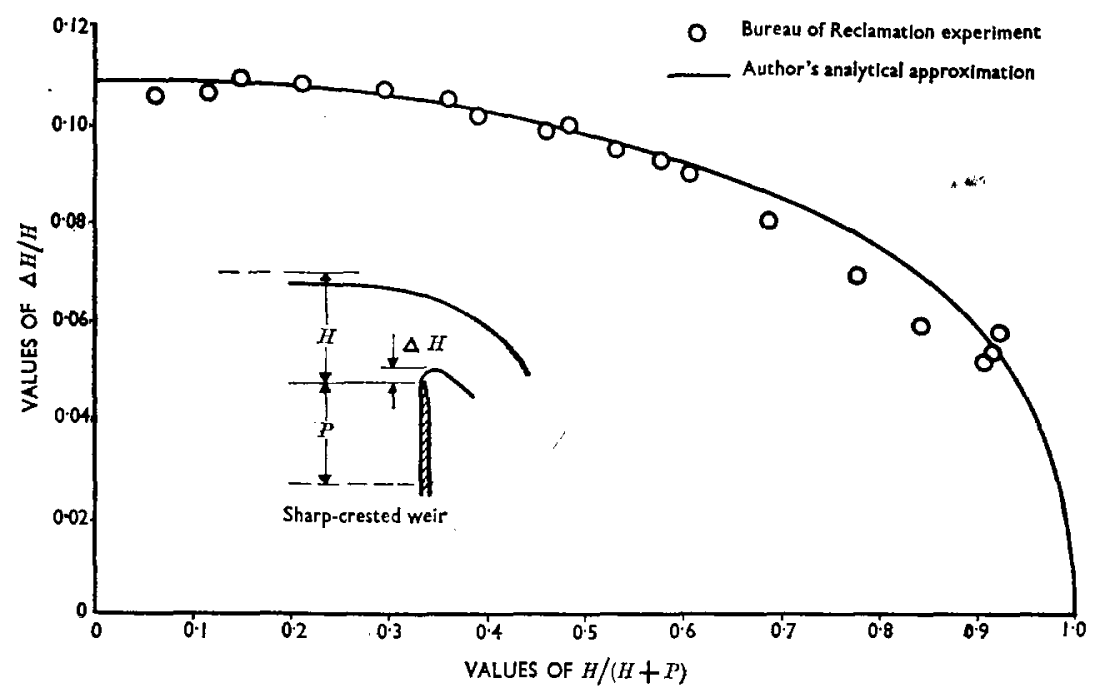

Fig. 15: COMPARISON OF AUTHOR's apProximation With EXPERIMENTAL Data

188. It should be observed that no suggestion had been made of any general similarity between the gravity-influenced weir flows and the gravity-independent flows through a slot or orifice; such an assumption was inadmissable.

189. A further step taken by the Author involved equating the displacement thickness of the boundary layer at the re-attachment location on the broad-crested weir with the maximum elevation of the preceding entry-bubble. This hypothesis was supported by some figures of Maskell, relating to a thin aerofoil at small incidence $\alpha$, which were reproduced in Table 7 .

190. The validity of the hypothesis, in its application to the broad-crested weir flow, would certainly require to be substantiated experimentally.

191. Obviously, an urgent requirement existed for further systematic tests which might most conveniently be undertaken by those laboratories with suitable apparatus existent. Indeed, several correspondents indicated their readiness to initiate such investigations. In that connexion, the Author would be prepared to act in a liaison capacity if required.

192. The Author's strictures on uncontributive testing appeared to have disturbed a number of contributors. Accordingly, some elaboration of remarks in the Paper was appropriate.

193. For convenience, most testing was undertaken in relatively narrow laboratory flumes, generally without much regard for the variable influence of side-wall 
TABLE 7: AerofoIl: NACA 64A006

\begin{tabular}{l|l|ll}
\hline$x / c$ & $\begin{array}{c}\delta^{*} / c \\
\left(\alpha=5^{\circ}\right)\end{array}$ & $\begin{array}{c}\delta^{*} / c \\
\left(\alpha=7^{\circ}\right)\end{array}$ \\
\hline 0.025 & 0.008 & 0.012 & $*$ Up to and includ- \\
0.05 & $0.010^{*}$ & 0.020 & ing the traverse so \\
0.10 & 0.010 & 0.032 & marked, there was \\
0.15 & 0.007 & 0.0405 & reverse flow near \\
0.20 & 0.0075 & 0.046 & the wall. \\
0.30 & 0.005 & $0.048^{*}$ & \\
0.40 & - & 0.045 & \\
0.50 & 0.009 & 0.041 & \\
0.60 & -- & 0.040 & \\
0.70 & 0.012 & - & \\
0.90 & 0.016 & - & \\
\hline
\end{tabular}

$\delta^{*}=$ displacement thickness of upper-surface boundary layer

$x=$ distance downstream of leading-edge, $c=$ chord

proximity on the flow. One possible consequence deriving from the displacement effect of the side-wall boundary layer was illustrated in Fig. 16; conceivably, the depth of flow over the crest could hardly remain unaffected in such circumstances. Additional phenomena might be induced by the thickening and possible separation of the corner boundary layers in the presence of a decelerating main flow. Therefore, if two-dimensional conditions were to be investigated, the ability to exclude in some way the influences alluded to above was vital.

194. At this point it might be observed that, in an endeavour to provide a test of two-dimensional theory, the experimental material considered in the Paper had been selected to possess high $B / H$ values (well in excess of 5 in all but a few instances). This explained one reason why the Author was compelled to prefer the results of experiments performed by Bazin so long ago, a point of criticism in the discussion.

195. In the case of the usual laboratory-flume set-up, not only did the value of $B / H$ change as the weir head was varied but so also did the Reynolds number, the $L / H$ and $H /(H+P)$ ratios, possibly also the relative geometry of the approach section, and the relative roughnesses. Unless some thought was given and action taken to separate out the individual effects of these various influences, the test results might be virtually useless in so far as advancement of understanding of the flow mechanism was concerned.

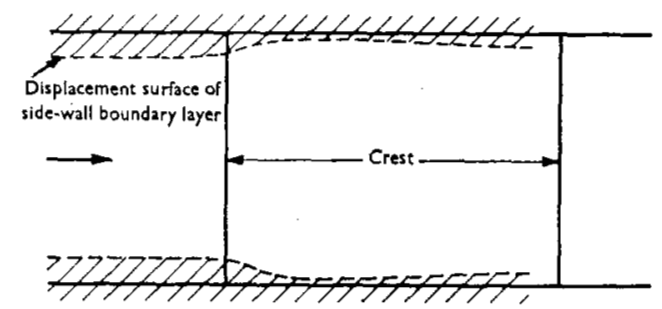

Fig. 16: Plan View of BROAD CRESTed Wetr INSTAlled IN LABORATORY FLUME-POSSIBLE EFFECT OF SIDE-WALL PROXIMITY 
196. As a final comment on the role of experiment, it was obvious that wellplanned and executed experimental work had a tremendous potential value. But to qualify for inclusion in that category it was essential that all environmental details of the test must be recorded, e.g. the precise degree of crest entry-edge sharpness, the crest roughness, etc. Regard must also be paid, in planning the experiment, to the necessary overall accuracy of the results in order that justifiable and significant conclusions might be presented.

197. Several contributors had suggested that the occurrence illustrated by Fig. 3 , involving a 'control' at the crest boundary layer transition, was unlikely. The Author disagreed and believed that several factors, principally the influence of flow acceleration over the upstream region of the crest, had been overlooked in expressing those views.

198. It was well established that in the presence of a favourable pressure gradient, transition from laminar to turbulent flow within a boundary layer, on a sufficiently smooth surface, was unlikely to take place even at relatively high values of Reynolds number (see reference 3, p. 423). If, however, at those high Reynolds numbers the acceleration of the mainstream flow was subsequently relaxed, then an abrupt transition to turbulent flow inevitably ensued. These conditions were those to which the boundary layer following a smoothly contoured crest-entry might be subjected and hence there was no doubt in the Author's mind that Fig. 3 would be representative in the particular circumstances outlined.

199. If it was accepted that, through the stabilizing effect of the crest-entry flow acceleration, abrupt transition within the crest boundary layer might occur towards mid-crest length, then along the turbulent portion of the crest boundary layer, there was likely to exist an accelerating outer flow due to drawdown. This would keep the displacement thickness small relative to that of the laminar layer at transition, so leading to the establishment of a control at the transition location.

200. Tentative support for the validity of the foregoing argument was provided by certain experimental evidence. ${ }^{9}$ Those observations related to a V-section Venturi flume in which any such effective hydraulic drop was magnified considerably. Surface level drops, under certain conditions, were indeed observed. Moreover, it was only by the assumption of supercritical flow downstream of the surface drops that the recorded discharge coefficient values could be justified theoretically. Further appropriate experimental investigation was undoubtedly needed.

201. Before closing these introductory remarks, some allusion should be made to a controversy concerning the validity of representing the real discharge as ideal flow over the 'displacement surface'; that was the concept initiated by Ippen and adopted by Delleur, the Author, and others. Subsequent to a study of reference 53, and the receipt of a personal communication from Professor Kindsvater (in which dislike of the above mentioned analytical device was expressed and an alternative preferred method indicated), the Author drew the attention of Messrs Allan, Ackers, and Harrison to the divergency of view. The critical comment with which those persons have responded was especially welcomed.

202. Unfortunately, Professor Kindsvater was unable to take part in the written discussion. He mentioned, however, that his ideas ${ }^{53}$ had been elaborated in a forthcoming U.S. Geological Survey Water-Supply Paper ; ${ }^{56}$ the publication of that report, which was expected also to cover the flow over embankment-shaped weirs, was awaited with considerable interest.

203. Professor Kolupaila, in the opening paragraphs of his contribution, referred to the enormous past effort devoted to attempts to solve the problem tackled by the Author in the present Paper and, in company with other contributors, he appeared surprised that it was necessary to appeal to experimental work of the last century.

204. Those observations surely constituted a damning indictment of the efficacy of much recent investigation in this sector of hydraulics, since a disproportionately small advancement of knowledge had accompanied that prodigious expenditure of 
energy. Few, if any, of these experiments had been so carefully planned and executed as those of Bazin whom Rouse and Ince ${ }^{51}$ labelled 'an impeccable experimenter'.

205. The reason for this notable lack of progress, the Author believed, resided in the paucity of soundly-based theoretical speculation; experiment was most fruitful when designed to test some analytical prediction.

206. The Author thanked Professor Kolupaila for drawing attention to an inconsistency in Fig. 2 which was intended to portray a slightly unsteady limiting condition to which the continuity relation could not be applied directly. To correct this inconsistency, Fig. 2 of the Paper should be replaced by a new figure, Fig. 2a. Reference to Fig. $10^{38}$ would show that the form illustrated in Fig. 2a was a possible steady fiow at relatively high downstream levels.

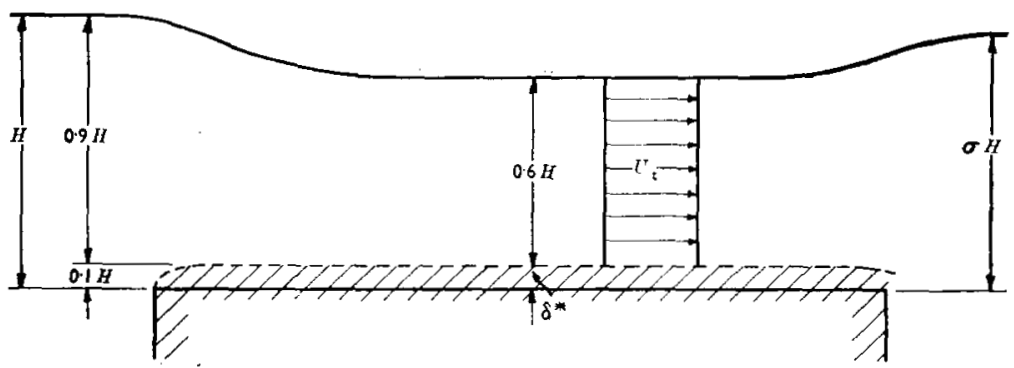

Fig. 2a: Conditions AT INCIPIENT SUBMERGENCE

207. The boundary layer separation criterion given in the Paper was essentially equivalent to the specification of a limiting pressure rise sustainable by the crest boundary layer prior to separating. That criterion could be expressed alternatively as

$$
\left[\Delta h /\left(U_{\mathfrak{t}}^{2} / 2 g\right)\right]_{\mathrm{iim}}=0.5,
$$

where $\Delta h$ was the abrupt increase of static head. The relationship gave, as before, $\sigma=0.85$.

208. Finally, Professor Kolupaila raised an objection which might be overcome by a redefinition of some of the parameters together with an appropriate readjustment of coefficient values. Thus the Reynolds number could be redefined as

$$
\frac{(2 g h / 3)^{0.5} h}{\nu} \text { or } \frac{g^{0.5} h^{1.5}}{\nu}
$$

\section{$L / H$ changed to $L / h$ and $H /(H+P)$ to $h /(h+P)$.}

209. Dr Rajaratnam, making reference to an experimental study at Bangalore, presented an expression for $C$ intended to be valid over his 'broad-crested weir range'. But that empirical relation could apply only to a particular investigation since it did not incorporate Reynolds number, neither did it embody a relative roughness parameter nor the ratios $H /(H+P)$ and $B / H$. By contrast, rationally-based expressions were capable of predicting $C$ for full-scale structures. Incidentally, a non-dimensional form for $C$ was surely to be preferred.

210. In the discussion of Woodburn's paper, ${ }^{26}$ cited by Dr Rajaratnam in his allusion to the crest-flow depth, Woodward made the following significant comment: 'Whenever flow is near the critical depth and critical velocity, the depth is in a condition of peculiar unsteadiness... This state of uncertainty does not extend, however, to the quantity of flow ... The result is that the very same conditions 
which are most unfavourable for an experimental measurement of critical depth are most favourable for the prediction of quantity of flow'.

211. Admittedly, 'drawdown' at the downstream end of the crest did induce local thinning of the crest boundary layer, but within the limits of relative crest length specified in the Paper the value of $\delta_{\text {max }}^{*}$, computed by using the actual crest length, could not be much in error on that account.

212. In reply to the comment on modularity, the Author believed that the value of the limiting depth ratio $\sigma$ was strongly dependent on the magnitude of the prevailing Reynolds number, a parameter which the contributor disregarded. Thus, laboratory tests could give a variety of results for $\sigma$.

213. With regard to the angle of $15^{\circ}$ indicated in Fig. 5 for spreading of the turbulent shear layer, it was emphasized that, as was asserted in the Paper, the figure referred only to an initial stage in the formation of the separation region; the aim was to justify a mean re-attachment location for the $R_{\mathrm{H}}$ range considered.

214. For an aerofoil, the study of bubble behaviour had to take account of incidence changes. In the case of the weir-crest geometry considered, the condition for re-attachment was always satisfied. The Tani-Owen and Klanfer criterion was effectively matched by the stipulation in the Paper that $R_{\mathrm{H}}$ must exceed 50000 . Guidance of greater significance to the present study was forthcoming, it was suggested, from reported investigations of flow over a backward-facing step.

215. The Author had exchanged letters with Professor Rouse who had drawn attention to interesting work which he had carried out ${ }^{33}$; but a careful examination revealed that nothing therein had a particular bearing on the present investigation.

216. The Author could not agree that theoretical speculation should be postponed. As Professor Kolupaila pointed out, collection of experimental material had extended over a space of more than 100 years and yet progress in the elucidation of the flow mechanics had been pitiably small. What was urgently required were plausible hypotheses to guide the experimenter.

217. Professor Hom-ma asserted that the velocity switched from subcritical to supercritical in the flow across the weir crest, and implied that the transition between these types of flow occurred over the entry bubble.

218. However, the fact that experiment indicated that $C$ was certainly not independent of the length of crest discounted the validity of hypothesizing a 'control' location at the entry bubble. Fig. 6 showed a streamwise length of crest which was less than the minimum considered in the Paper; in consequence, considerable flow acceleration would prevail across the crest.

219. Professor Hom-ma pointed to the physically unlikely occurrence of $\delta_{\max }^{*}$ at the termination of the crest where drawdown of the flow surface existed. In Fig. 1, $\delta_{\max }^{*}$ was purposely shown slightly upstream of the crest end in order to emphasize just that point; however, the error involved in computing the boundary layer $\delta_{\max }^{*}$ on a basis of the actual crest length, instead of a dimension slightly less, should be quite negligible.

220. With regard to the remark concerning records of velocity distributions within the flow over the crest, Keutner ${ }^{43}$ gave the results of some such measurements which, in general, tended to support the validity of the Author's flow model.

221. Dr Agnew outlined a means of extending the analysis, as presented in the Paper, in order that rough surface conditions, which were more likely to obtain in practice, might be embraced.

222. Although the result of Dr Agnew's work, equation (8), would seem to provide a target towards which experimenters could usefully direct their efforts, it would be wise first to have experimental verification for a number of the more fundamental assumptions of the Author's analysis. Notwithstanding that reservation, Dr Agnew's suggested procedure was exceedingly valuable in providing a general method of taking account of the roughness influence in a rational manner. Of course, 
some details of the method might need amendment. For example, it might be necessary to change the exponent $1 / 7$ to suit the circumstances, but that exigency was envisaged.also for the main analysis described in the Paper.

223. Mr Wallis provided welcome authoritative comment on the detailed flow mechanism associated with the crest-entry separation bubble.

224. The Author agreed with Mr Wallis' view that an upstream advance of transition within the separated shear layer, as high Reynolds numbers were approached, would probably be reflected in a further variation in the value of $C$; a variation which the normal laboratory tests at low Reynolds numbers would fail to reveal. More experimental investigation of this aspect was clearly necessary.

225. The anticipated change in the value of $C$ for the square entry-profile at high Reynolds numbers would probably not be evidenced when the included angle of the angular entry-profile was increased substantially beyond $90^{\circ}$. This latter form seemed to be the more commonly adopted. Thus, although an angular entry-profile was valuable as a means of inducing-through the agency of the separation bubble which developed-an early transition within the crest boundary layer, nevertheless, a severe restriction on the relative extent of the bubble also appeared to be efficacious.

226. As $\mathrm{Mr}$ Wallis implied, once the intricate detail of the flow mechanism throughout the relevant Reynolds number range had been laid bare, the time would be ripe to consider designing certain special features into the structure aimed at securing the boundary layer behaviour required.

227. Mr Ackers and Mr Harrison gave in extenso interesting views on the assumptions implicit in the Paper's analytical treatment.

228. The Reynolds number entered into the estimate of the crest boundary layer relative thickness only after being raised to the one-fifth power; thus the approximation for $U_{t}$ made in drawing up Table 1 was reasonable in view of the other assumptions adopted in regard to the layer growth. Mr Ackers had used a similar approach. ${ }^{12}$

229. Mr Ackers' and Mr Harrison's discussion on the validity of the Ippen concept was valuable and should be read in conjunction with the analysis contained in the contribution of $\mathrm{Mr}$ Allan and $\mathrm{Mr}$ Williams.

230. Horton, ${ }^{5}$ alluding to tests which included those of Bazin, stated that: "The models used in weir experiments have usually been constructed of planed and matched timber.' That remark appeared to be the only clue available as to the surface condition of the Bazin crests. An extension of the Author's analysis to take account of crest roughness had been presented in the discussion by Dr Agnew.

231. It was agreed that an accurate assessment was needed of the errors which arose from application of the rectilinear flow theory to curvilinear flow conditions which were inevitable when, with increase of head, the relative crest lengths approached and then fell short of the low limit specified tentatively in the Paper.

232. It should be noted that application of the Author's analysis was ruled out at very low heads by the stipulation that the values of $R_{\mathrm{H}}$ must not be less than 50000 .

233. Submergence had been considered in the Paper for the case of $P \rightarrow \infty$ only. In regard to assessment of the submergence limit, the attention of $\mathrm{Mr}$ Ackers and $\mathrm{Mr}$ Harrison was directed to the Author's reply on a submission by Professor Kolupaila.

234. It was incorrect to assert that the Author had argued against the use of any particular entry-profile; much more must be revealed about the relevant flow mechanics before it would be possible to present well-founded opinion on optimal design. All that the Author aimed to do was to uncover the hydraulic advantages and disadvantages possessed by the alternative types of entry-profile; environmental operating conditions had not been considered.

235. Some additional discussion of the conditions illustrated by Fig. 3 had been given previously. The circumstances tested by Dhawan and Narasimha ${ }^{42}$ did not accord with the weir-crest flow conditions and their findings could not, therefore, form a guide to behaviour of the weir-crest boundary layer. 
236. The assumption by $\mathrm{Mr}$ Ackers of fully-developed channel flow across the crest could not lead to more than a fortuitously fair estimate of the viscous effects in particular circumstances, nor could occurrences such as that of Fig. 3 be predicted. Should his method be applied to the case of an angular throat entryprofile, as had actually occurred, a wide margin of error might result. This illustrated the danger of adopting an empirical approach.

237. The Author appreciated that his flow model for the square crest-entry geometry involved an inconsistency (which would probably be absent in the case of the more usual design of weir embodying a sloping upstream face) arising from the simplifying assumptions applied to the growth of the entry-bubble wake. That did not imply that the estimate for $C$ was likely to be much in error on this account. Experimental evidence suggested that for moderate values of $L / H$ the flow approaching the downstream end of the crest was unlikely to have acquired a fully developed velocity profile. Therefore, further experiment, directed towards discovering how to readjust the simplified model conditions until the actual flow was adequately represented, was needed.

238. In answer to $\mathrm{Mr}$ Addison, accurate observations of velocity distributions within truly two-dimensional crest flow would certainly resolve numbers of existing uncertainties. But the difficulties in effecting such measurements were considerable, since the flow pattern was exceedingly sensitive to disturbance which was likely to arise from the insertion of a measuring probe.

239. Mr Addison was not alone in his dislike of the term 'separation bubble' used in the context of the Paper; a similar point was made by Professor Rouse in a private communication. However, that designation now seemed too firmly established to hope for any change in terminology.

240. A partial reiteration of the Author's strongly held views seemed appropriate in reply to $\mathrm{Mr}$ Addison's final paragraph. Most essential, before serious consideration was given to optimal geometry of these structures, was a greater measure of understanding of the relevant flow-mechanism detail than presently existed. Absence of such understanding tended to lead to a multiplicity of designs, none of which might approach the optimum. It would be most regrettable if ad hoc designs were incorporated into the national and international standard codes without sufficiently thorough background research.

241. Support for the view expressed above, it was believed, would follow a study of the current situation in respect of closed-conduit flow measurement by p.d. device.

242. Mr Allan and Mr Williams presented conclusions of considerable importance arising from their investigation of the significance of the Ippen approach. The Author had utilized that approach without, however, deeply probing its validity.

243. Mr Zanker opened his remarks with a statement on the relative influence of the weir entrance separation bubble and the crest boundary layer growth as they affected the value of $C$. That assessment applied only to the square-entry geometry; for the more usual weir-section having a sloping upstream face, the contributive proportions would not be so greatly different.

244. Dr Engel and $\mathrm{Mr}$ Stainsby directed attention to significant experimental evidence from recent and not-so-recent German work.

245. It should be noted that Dr Keutner, in presenting observations of the entry separation-bubble size, added a rider which, in the Author's translation, appeared as follows: 'It is extremely difficult to indicate accurately the upper limit of the water roll-even to any extent.' This seemed to imply that a considerable degree of uncertainty was to be attached to his quoted figures.

246. In connexion with the appearance on the weir crest of standing waves, the Author's belief had always been that it was boundary layer separation initiated by an adverse pressure gradient that gave rise to such waves. This view was put forward in reference 9 together with some experimental support. In the case of a relatively long crest with abrupt entry, the nappe initially plunged over the entry bubble; this 
was followed by a tendency for the surface level to rise, thus imposing an outer-stream deceleration on the crest boundary layer. Immediately downstream of the entrybubble re-attachment region, the crest boundary layer was in a condition particularly sensitive to separation inducements; this was especially so at the low Reynolds numbers characteristic of laboratory tests.

247. It was interesting to observe from Fig. 10 that the crest standing waves disappeared as the head, and so the Reynolds number, was increased. At very low Reynolds numbers laminar re-attachment might exist owing to the strongly stabilizing influence from the main-flow acceleration at the crest entrance. If the crest was bounded by longitudinal square corners, separation would be triggered by even the smallest extent of outer-flow deceleration in such circumstances.

248. Thus the answer to Dr Engel's and Mr Stainsby's query in $\S 149$ was that the separation bubbles or rollers giving rise to the crest standing waves were separate from and downstream of the crest entry separation bubble. Boundary layer theory could be appealed to, as explained in reference 9, to demonstrate that a separation bubble must exist beneath these waves.

249. Dr Engel and Mr Stainsby appeared to be under the impression that there was discord between the Author's hypotheses and Dr Bretschneider's findings; but that seemed to be a mistaken view. Thus, if the $R_{\mathrm{h}}$ values were worked out for the points of intersection between the 'variable' and 'constant' portions of the discharge coefficient curves of Fig. 11, those values all approximated to 50000 -the lower limit for which it had been estimated that the Author's theory would apply. On the other hand, the $R_{\mathrm{h}}$ values at which the crest standing waves disappeared turned out to be double that figure, i.e. about 100000 .

250. It was agreed that a switch from a smooth to a roughened crest would increase the likelihood of crest standing waves arising in given circumstances.

251. Dr Engel and Mr Stainsby were thanked for pointing out in reference 48 that the Author's theory gave a prediction, for the weir with 1:1 entry slope, which agreed well with certain of Dr Bretschneider's experimental results.

252. It was agreed also that Dr Bretschneider's method of presenting the coefficient curves was not the best. As the head was increased the Reynolds number increased and the values of $B / H$ decreased. Each of these factors probably had a greater influence on the value of $C$ than the indicated variation in the value of $h / w$. In the Bretschneider experiments the combination of these influences appeared to have led to an invariable coefficient value when $R_{\mathrm{H}}$ was greater than about 50000 . Strictly, the Author's prediction of equation (5) applied only to $B / H \rightarrow \infty$.

253. Mr Lacey drew on wide experience in providing comment relating principally to the relative merits of angular and rounded weir-entry profiles.

254. In responding to those views, let it be said first that the Author believed the weir form with sloping upstream face to be the more usual in practice; the squareentry-edge type was introduced to provide a means of testing the validity of the general method of analysis proposed. Devices with angular-entry profiles were evidently widely used. ${ }^{54}$ Also, the success of the Parshall flume in its ability to meter an exceedingly wide range of flows might well be partly attributable to the angularities which characterized that design.

255. Secondly, the relative radii $r / H$ of moderately-rounded crest-entry profiles became small at high heads. This would lead to the formation of a bubble whose dimensions were not only indeterminate analytically, but subject to random variations from quite minor site influences. This last conclusion was reached from a study of available experimental results. Clearly, such behaviour was opposed to the attainment of accurate metering.

256. In the case of relatively large entry-radii which were evidently favoured by Mr Lacey, thin laminar boundary layers were likely to persist along the crest even at high Reynolds numbers, if the crest surface was smooth. The discharge might, in 
consequence, accord closely with the ideal, particularly if the reduction in the coefficient value due to boundary layer development was largely offset by an increase in the coefficient value arising from flow acceleration across the crest. The danger here, as the Author saw it, was that deposits on the crest-or other sources of disturbance-might effect a switch to turbulence in the boundary layer. The actual value of the discharge coefficient might then be radically different from the calibration value. Site checks of calibration figures were notably lacking.

257. Large entry-radii would seem to lead to unnecessarily expensive construction. Thus, if a rounded-crest entrance was to be adopted, no hydraulic advantage appeared to accrue from rounding in excess of the shape defined by the separation bubble outline for that particular head. It might be noted that Woodburn's experiments ${ }^{26}$ gave similar discharge coefficient values for radiused entry, where $r / H$ exceeded $0 \cdot 11$.

258. Concerning the question of distinguishing between the upstream gauge and total heads, the treatment in the early part of the Paper (see Figs 1 and 2) related to the simplified geometry where $P / H$ was large and hence the velocity of approach was negligibly small. This was the case also for those parts of the text illustrated by Figs 3 and 5.

259. With regard to the conjectures of $\mathrm{Mr}$ Singer and $\mathrm{Mr}$ Smith on the effect of sloping the crest, it would be realized that compensation in this way for the boundary layer growth was possible at one head only, whereas metering installations had to cope with a range of head.

260. Woodburn ${ }^{26}$ reported experiments with slightly inclined crests and those observations tended to support certain of the Author's hypotheses. Thus, it was found that the imposition of a gradual downward slope to the crest in the direction of flow was sufficient to suppress the standing waves which had appeared when the crest was level. This finding was interpreted by the Author as justification for his belief that boundary layer separation induced by a locally decelerating main flow was the basic cause for the appearance of standing waves on the level crest.

261. As would be expected, the coefficient of discharge for the sloping-crest weirs was found to decrease as the head was increased.

262. Dr Bunt suggested, as a means for correlating the experimental data, an alternative form of non-dimensional plotting. While this manipulation of results was certainly intriguing, the Author was not entirely convinced that much would be gained by adopting the method advocated.

263. Dr Bunt's empirical expression with constant discharge coefficient might be useful for certain applications. Indications that such expressions adequately represented experiment over a limited range of relative head had been put forward by Dr Engel and Mr Stainsby ${ }^{48}$ and even by Horton ${ }^{5}$. One possible explanation for this behaviour was that the crest boundary layer might require a greater distance than had been postulated in the Paper, before a normal velocity profile became established. Further experiment would shed light on this matter.

264. Birkhoff ${ }^{55}$ suggested that: "If we are too impressed by the dangers of approximation, we must despair at the outset of attaining any rational understanding of fluid mechanics. However, science was not built by timid or faltering hands.' That statement could hardly be bettered as an expression of the Author's philosophy, in pursuing the present theoretical investigation.

265. Apart from clarifying and elaborating certain matter in the Paper, the responses to contributors had had to be confined, somewhat unsatisfactorily, to further speculation. This must remain the situation until the additional systematic testing called for had been undertaken.

266. A clearly defined but highly speculative flow model had been put forward in the Paper. It was noteworthy that no well-based suggestions had been forthcoming in the discussion aimed at improving the model assumptions. The Author 
now looked for and would welcome, since that was the surest way of effecting advancement of knowledge, the presentation of reliable experimental evidence indicating that certain of his hypotheses required modification.

\section{REFERENCES}

24. S. Kolupaila. 'Bibliography of hydrometry'. Notre Dame Univ. Press, Indiana, U.S.A., 1961, pp. 720-727.

25. N. S. Govinda Rao and D. Muralidhar. Discharge characteristics of weirs of finite crest width. To be published in Houille Blanche.

26. J. G. Woodburn. Tests of broad-crested weirs. Trans Amer. Soc. civ. Engrs, vol. 96, Paper No. 1797, 1932, pp. 387-453.

27. H. Rouse. Discharge characteristics of free overfall. Civ. Engng, vol. 6, no. 4, pp. 257-60.

28. D. Muralidhar. 'Flow over weirs of finite crest width'. M.Sc. Thesis to be submitted to Indian Institute of Science, Bangalore.

29. N. S. Govinda Rao and N. Rajaratnam. 'Studies on Krishna Anicut'. Unpublished report to the Gulhati Commission, 1961.

30. 'Kodeveri Anicut'. Unpublished report of the Irrigation Research Station, Poondi, Madras, 1959.

31. N. Rajaratnam and P. K. Kandaswamy. 'Flow over circular weirs'. Unpublished report of the Irrigation Research Station, Poondi, Madras, 1959.

32. I. TANI. Critical survey of published theories on the mechanism of leading edge stall. Rep. Aeronaut. Res. Inst. Univ. Tokyo, vol. 27, no. 7, June, 1961.

33. H. Rouse. Distribution of energy in regions of separated flows. Houille Blanche, no. 3, May 1960, pp. 235-246 and no. 4, June 1960, pp. 404-411.

34. W. J. BAUER. Turbulent boundary layer on steep slopes. Trans Amer. Soc. civ. Engrs, vol. 119, 1954, pp. 1212-1242.

35. Ven Te Chow. 'Open-channel hydraulics'. McGraw Hill, New York, 1959, p. 198.

36. R. A. Wallus. Boundary layer transition at the leading edge of thin wings and its effect on general nose separation. Advances in Aeronautical Sciences (2nd I.C.A.S.), Pergamon Press, Oxford, etc, 1961, vol. 3, pp. 161-184.

37. P. Ackers and A. J. M. Harrison. 'Critical-depth flumes for flow measurement in open channels'. To be published.

38. H. A. Doeringsfeld and C. L. Barker. Pressure-momentum theory applied to the broad-crested weir. Trans Amer. Soc. civ. Engrs, vol. 101, 1941, pp. 934969.

39. P. ACKERs. 'Charts for the hydraulic design of channels and pipes'. Hydraul. Res. Paper 2. H.M.S.O., London, 1958, p. 46.

40. J. W. HaCkney. Discussion on reference 38, pp. 958-960.

41. C. E. Kindsvater and R. W. Carter. Discharge characteristics of rectangular thin-plate weirs. Proc. Amer. Soc. civ. Engrs, vol. 83, Paper 1453, December, 1957.

42. S. Dhawan and R. Narasimha. Some properties of boundary layer flow during the transition from laminar to turbulent motion. J. Fluid Mech., vol. 3, 1958, pp. 418-436.

43. C. KEurner. Strömungsvorgänge an breitkronigen Wehrkörpern und an Einlauf beuwerken. Bauingenieur, vol. 15, 1934, pp. 366-371, 389-392.

44. H. BrETschNeIDER. Abflussvorgänge bei Wehren mit breiter Krone. Institut für Wasserbau und Wasserwirtschaft, Mitt. 53, Tech. Univ. Berlin, 1961.

45. F. V. A. ENGel and W. StainsBy. On the meaning of unified equations related to weirs for measurement of open channel flow. Engineer, Lond., vol. 212, 1961, pp. 513-520. 
46. J. Einwachter. 'Wehre und Sohlenabstürze. Berechnung der Unterwasserspiegellage und Kolktiefe bei den verschiedenem Abflussarten!' Oldenburg, Munich and Berlin, 1930.

47. J. EINWACHTER. Wassersprung und Deckwalzenlänge. Wasserkr. u. Wasserw., vol. 30, 1935, no. 8, pp. 85-88. See Fig. 7 .

48. F. V. A. Engel and W. Stainsby. Broad-crested weirs: some notes on discharge coefficients. Engineer, Lond., vol. 214, 1962, pp. 537-538.

49. G. LACEY. Discussion on Paper No. 4814 'Design and construction of the Sarda Canal' by Sir Bernard D'Olier Darley. Min. Proc. Instn civ. Engrs, vol. 233, 1931-32, p. 192.

50. J. D. Atkinson and G. Cardiacos. Reconstruction of the Diyala Weir. $J$. Instn civ. Engrs, vol. 25, 1945-46, pp. 22-46. See particularly pp. 32 and 44.

51. H. RousE and S. INCE. 'History of hydraulics'. Iowa Institute of Hydraulic Research, 1957, pp. 249-250.

52. G. W. Hall. Application of boundary layer theory to explain some nozzle and venturi flow peculiarities. Proc. Instn mech. Engrs, vol. 173, 1959, pp. 837-870.

53. C. E. Kindsvater. Energy equation for partially developed free-surface flow. Civil Engng, vol. 31, no. 3, March 1961, p. 66.

54. C. van BeesteN. Hydraulic design of weirs. J. Inst Wat. Engrs, vol. 16, no. 5, August 10, 1962.

55. G. Birkhoff. 'Hydrodynamics-A study in logic, fact and similitude.' Princeton University Press, 1950 , p. 7.

56. C. E. Kindsvater. Discharge characteristics of embankment-shaped weirs. U.S. Geological Survey Water-Supply, Paper 1617-A, 1964. 